



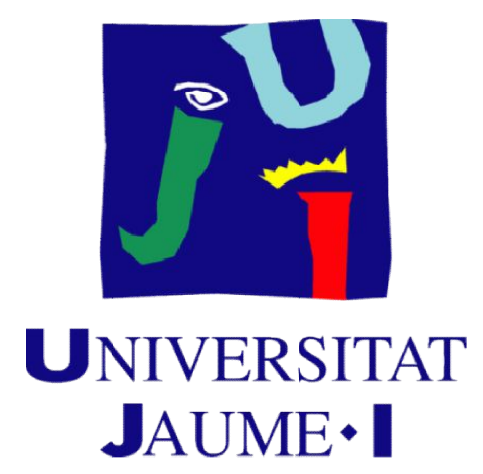

Programa de Doctorado en Ciencias

Escola de Doctorat de la Universitat Jaume I

\section{Hidrogelantes moleculares: Influencia de la presencia de surfactantes y desarrollo de nuevos gelantes bis-urea}

Memoria presentada por Juan José Ojeda Flores para optar al grado de doctor por la Universitat Jaume I

Doctorando:

Juan José Ojeda Flores
Director:

Juan Felipe Miravet Celades

Castelló de la Plana, Junio 2018 



\section{Agradecimientos institucionales:}

Este trabajo ha sido financiado por Procter \& Gamble Europe SA. El trabajo que se presenta se ha desarrollado bajo las condiciones especiales establecidas en el contrato de investigación entre la Universitat Jaume I y la compañía N.V. Procter \& Gamble Europe $S A$ y debe de ser tratada como estrictamente CONFIDENCIAL bajo los términos del artículo regulador 25 en el RD 99/2011.

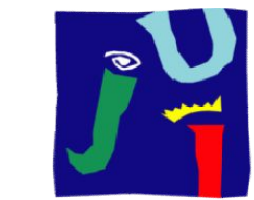

UNIVERSITAT

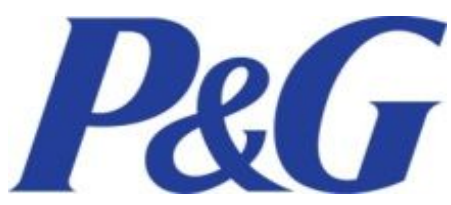

$\mathrm{JAUME} \cdot \mathbf{I}$ 



\section{Agradecimientos}

Todo en esta vida tiene un inicio y un fin, sino recordad a Gandalf cuando le da el anillo a Frodo y le dice "es el anillo único, forjado por el señor oscuro Sauron, en los fuegos del monte del destino, arrebatado por Isildur de las mismas manos de Sauron" y todo lo que tiene que pasar hasta destruir el anillo (tres películas extendidas con un total de $11 \mathrm{~h}$ y 37 minutos)...... es por eso que voy a intentar no dejarme a nadie que haya sido importante para mí en este largo y fascinante camino.

Todo empieza en el año 73 del siglo pasado (tranquilos no se me ha ido la cabeza, no va a ser tan largo), es el año de mi nacimiento y de los dos primeros discos de Bruce Springsteen, ${ }^{1,2}$ casualidad? Digo esto porque no hay manera mejor de explicar estos años hacia el monte del destino que a través de la música que he compartido con mis sufridos compañeros.

Por lo tanto al primero que quiero nombrar es al Boss, gracias Juan por apoyarme en los momentos difíciles del camino, por saber dirigir un grupo con una mezcla de trabajo y buen rollo, muy importante para que se disfrute y venir con una sonrisa al laboratorio. Y como se trata de enlazarlo todo con la música, aunque Malú no es Bruce, te diría "me has enseñado tú, tú has sido mi maestro...".

Una cosa que no me ha faltado son jefes, gracias Bea por estar dispuesta ayudar en todo de lo que no tenía ni idea antes de entrar en el laboratorio (SEM, TEM, bibliografia, etc..). Además has sido víctima del virus Bruce, viniendo a Madrid, gran concierto y además en primera fila. Tienes que volver para que cante una de las que más te gusta, "Rendezvous". 4

Otro de los "jefes", que no ha sido mío pero si de Carles y Ana, es Paco, agradecerte que siempre hayas tenido la puerta abierta a cualquier duda que me surgiera.

Más jefes, quiero agradecer a $P \& G$ el soporte económico necesario para que todo este trabajo se pudiera realizar. Gracias Susana por enseñarme tanto sobre la relación entre la empresa y la investigación. Has conseguido que la distancia entre ellas sea la mínima posible. Gracias a Johan por aportar ideas muy interesantes que nos ha permitido mejorar en nuestro trabajo. Tampoco quiero olvidarme de Evelyn, por ayudar a que mis estancias 
en el laboratorio en Bruselas fueran mucho más sencillas. Por supuesto gracias a $A$ bel por ser todo un pozo de sabiduría reológica.

En cuanto a mis compañeros, para que nadie se sienta menos importante, los voy a ordenar de manera cronológica. Y como diría un tal Sabina, Marta "de sobra sabes, que eres la primera...". Gracias por enseñarme las primeras síntesis de esos compuestos tuyos tan largos ("los tetrapeptai"), de esos primeros meses surgió mi primer objetivo, mis futuros compuestos serian más fáciles de sintetizar (véase capítulo 4). Todas las dudas que me has resuelto son infinitas igual que tu gran corazón. Para mí, siempre te lo he dicho, eres una crack dentro y fuera del laboratorio.

Después llegó Cristina, la de Radio 3, mira que me esforcé para que te gustase Bruce, pero nada, al final sino puedes con el enemigo te unes a él y me acabó gustando un poco Radio 3. Aparte de bromas gracias por ser tan buena compi de bancada, he aprendido y me he divertido a partes iguales, aunque gracias a ti, casi me despeño con Marta en Bressanone.

Y entonces vino Vicent y como Bilbo Bolson le dijo a Frodo "yo ya soy muy mayor, ahora te toca a ti, toma el anillo y suerte". Gracias por enseñarme muchas cosas, pero sobretodo el difícil pero fascinante mundo de la reología. No has sucumbido a Bruce, por falta de tiempo, pero recuerdo tu buenísima versión de "Bohemian Rhapsody" en el karaoke.

En cuanto a Maria Dolores no pude hacerte de Bruce porque tú ya eras friki del Game of Thrones por lo que te acompañé en esta enfermedad. Recuerdo los lunes picándote con spoilers del último episodio y que tú lo veías los martes. Gracias Khaleesi por tus enseñanzas.

Por otra parte, Cesar y Santi, los cerebros sintéticos puros del laboratorio. Gracias porque si tenía cualquier duda sintética iba a vosotros antes que a Google. La música del Boss no entró en territorio colombiano pero en Santi si, incluso cambiando vinilos, gracias por Luckytown. $^{7}$

Y como no voy a nombrar a los extranjeros del grupo, el indio y el portugués.

Nishant el hombre 2.0, polifacético, igual te hace una reacción catalítica dentro de un gel que 100 flexiones por minuto. Crack de la química y muy buena persona. Y por supuesto 
Bruce entró en él, solo quería que le pusiese "Fire", ${ }^{8}$ canción que le va con su lado más "bollywoodiense".

Marco, mi hijo adoptado. Gran amigo, lo hemos pasado muy bien. La verdad es que cuando Bea me dijo que venía un portugués, recelé porque mis pocas referencias no son muy buenas, Mouriño, Cristiano y Pepe. Pese a todo demostró tener un corazón que no le cabe dentro y ser muy buen chaval. Eso sí, al revés que Nishant, empezó hablando bien en español y acabó con el portuñolo que no hay quien lo entienda. Y por supuesto Bruce está en él, y como todos conocemos sus gustos por el sexo opuesto, la canción que más le gusta es "Girls in the summer clothes". ${ }^{9}$ Y por último sabes que siempre que vengas por la aldea tienes unas pelotas rellenas de crema de la pastelería Giménez para ti o para tus gallinas. Por cierto te voy a pagar un curso online de Chemdraw para que aprendas.

Otro extranjero más, el gallego Jorge. Un crack que triunfa en Estrasburgo y pronto en Holanda. Padre y doctor en tres años, que más se puede pedir. Ahora sí, el laboratorio aun se está recuperando del $\mathrm{CH}_{2} \mathrm{Cl}_{2}$ que te fumaste en la columna. Gracias por todo, incluido la tarte flambée en el restaurante “Au Brasseur” y la lucha con Ryanair. Ánimo con el Depor, el año que viene volverá a primera.

Y cómo olvidarme de mi compi procteriana, Silvia (ó Siiiiiiilviaaa como decía Marco) triunfando en el país Vasco. Compartimos alegrías, penurias, barridos de frecuencias y estreses, como siempre decimos tenemos en común el "reomordor". Gracias a tu trabajo previo, fue más fácil para mí las medidas reológicas. Eso sí, siempre te quedará el resquemor que le caí mejor a Axelle que tú.

El siguiente son palabras mayores, como diría Bruce, mi amigo, mi hermano, Carles. Pocas veces en esta vida se tiene la agradable sorpresa de encontrar a alguien tan buena persona, con la que puedes trabajar 8 horas y se te hacen cortas. Siempre dispuesto a echar una mano a quien se lo pida pese a que esta en 150 experimentos suyos a la vez. Y encima lo he hecho de Bruce $100 \%$. La canción que más lo define es "No Surrender"10 porque siempre que empieza un experimento no se rinde, es incansable. Aunque no te perdono que digas que la canción de "Thunder Road"11 es un plagio de "un mundo ideal" de Aladdín, Bruce no copia, le copian a él. Gracias por todo amigo y cuando te acuerdes del pesado de JuanJo escucha la canción "Blood Brothers" 12 porque eso para mí es lo que somos. 
Una de las cosas que pensé cuando conocí a $A \boldsymbol{n a}$ es que el futuro del grupo no peligraba, gran investigadora y mente brillante, gran persona y mejor compañera. En cuanto a la música de Bruce, no se quejaba, pero en cuanto salía al RMN aprovechaba para poner un mix de YouTube de Sia, donde la niña en la canción Elastic Heart ${ }^{13}$ es de lo más inquietante que se ha visto desde las niñas del pasillo de El Resplandor.

De la última etapa aunque no he tenido mucho tiempo para estar con ellos quiero nombrarlos, Carla sabes que te he dicho que me quito el sombrero por obtener la beca de Procter espero que vaya muy bien postdoctoralmente hablando. Diego aunque seas un poco bastante merengue me caes bien y por supuesto veo que eres un gran fichaje para el grupo, aunque he de decirte que musicalmente hablando estas perdido desde que escuché en el laboratorio que habías puesto el Reggaeton lento. ${ }^{14}$ Bárbara, Hector he coincidido muy poco pero os deseo que todo os vaya bien en el grupo.

Hay muchos más que han ayudado de alguna manera en esta tesis y perdón si me dejo alguno. Tenemos a Carolina (cuantas veces te hemos cantado Carles y yo... Sweeeeet Caroline), ${ }^{15}$ Andreu (espectacular experiencia en el Dry Congress o SECO en Port Leaucate), el gran Fabriccio incansable generador de ideas y gran tifossi italiano, Miriam megacrack triunfando en Heidelberg, visitantes italianas como Paola y de Bulgaria como Silvia e Iva. Agradecer la ayuda técnica de Javi y Maruxa (TEM y SEM o viceversa...siempre me lio), Cristian y Pedra, el doblete espectroscópico. Gracias también al Instituto Universitario de Ciencia de los Materiales (ICMUV) de la universidad de Valencia y en concreto al técnico superior de investigación David Vie por dejarme utilizar el reómetro dándome todas la facilidades del mundo. Gracias biológicas a Eva por abrir su laboratorio a mis geles, además del trabajo oscuro de cuidar y alimentar las células que se han usado en esta tesis. Agradecerte tu apoyo junto con Juan Murga en diversas etapas de mi vida universitaria. Gracias también a Rocío, mai güaif, sin ella la parte biológica de esta tesis directamente no se habría hecho.

Por supuesto quiero agradecer a mis padres y resto de mi familia que me han ayudado en todas las etapas de mi vida, bachillerato, carrera y finalmente doctorado. Gracias a su apoyo incondicional en los momentos difíciles he sido capaz de llegar hasta aquí. Y lo que yo siempre digo a todo el mundo no hay nada más clarificador en esta vida que subir sacos de cemento de $50 \mathrm{~kg}$ a un tercero sin ascensor para que te entren unas ganas tremendas de estudiar. 
Aparte de los compuestos que he sintetizado en este trabajo, 39 de urea y unos cuantos más derivados de valina, si hay una síntesis de la que estoy realmente orgulloso es la de mis dos preciosos hijos.

Justo cuando terminó mi carrera bioquímica apareció $\boldsymbol{A l b a}$, una rubia de ojos azules de la que todo el mundo que la conoce desconfía de mi paternidad, pero en el momento que dice una parida se sabe que es hija mía. Ella es una de la que más ha sufrido con el trabajo y estrés que conlleva hacer una tesis. Quiero agradecerle que haya aguantado mis cambios de humor. Y decirte que siempre te querré aunque te hagas de letras. Y que no se me olvide que fue la primera revisora de mi tesis.

Y después llegó Pablo el clon de Alba, otro rubio y peligroso, las dudas de mi paternidad siguen creciendo en la gente. Menos mal que la tesis se acaba porque la energía de Pablo puede conmigo y con su madre.

Y por supuesto la persona más importante de mi vida, Rocio. Llegó en el 92 como las olimpiadas de Barcelona y con ella empecé el COU bueno. A partir de ese momento todo fue más sencillo. Eras, eres y serás un ejemplo a seguir. Muchas canciones de Bruce nos han acompañado en nuestro camino, por ejemplo "Brillant disguise" 16 antes de conocer la letra o "Lucky town", 7 aunque una que te gusta mucho y te define es "Tougher than the rest", ${ }^{16}$ ya que eres más fuerte que el resto aunque no lo creas. Sin ti esta tesis hubiera sido imposible, gracias a tu apoyo incondicional he podido salvar los obstáculos que la vida te pone. Y si esto no fuera poco has dado sentido a mi vida con esos dos hijos que me has dado, que como decimos siempre...que aburrida era nuestra vida antes. Espero que sigas apoyándome igual pero ahora estudiando opos, la cuestión es no parar.

Y por último quiero mencionar a la otra mujer más necesaria para entender lo que soy ahora mismo en mi vida. Un ejemplo de sacrificio, amor y cariño sin esperar nada a cambio. Gracias mami por ser tan buena conmigo y aunque tus recuerdos desaparecen poco a poco, yo trataré de no olvidar como has sido conmigo para tratar de ser un buen ejemplo para mis hijos y recordarles cómo fue la yaya, ante todo una gran persona. 


\section{Bibliografía musical}

(1) Springsteen, B. Greetings from Asbury Park, N.J.; 1973.

(2) Springsteen, B. The Wild, the Innocent and the E Street Shuffle; 1973.

(3) Malú. Aprendiz; 1998.

(4) Springsteen, B. Tracks; 1998.

(5) Sabina, J. Yo, mi, me, contigo; 1996.

(6) Queen. A Night at the Opera; 1975.

(7) Springsteen, B. Lucky Town; 1992.

(8) Springsteen, B. Live / 1975-85; 1986.

(9) Springsteen, B. Magic; 2007.

(10) Springsteen, B. Born in the U.S.A.; 1984.

(11) Springsteen, B. Born to Run; 1975.

(12) Springsteen, B. Greatest Hits; 1995.

(13) Sia. 100 Forms of Fear; 2014.

(14) CNCO. Primera cita; 2016.

(15) Diamond, N. Brother Love's Travelling Salvation Show; 1969.

(16) Springsteen, B. Tunel of Love; 1987. 
A Rocío,

Alba y Pablo.

"Si os apasiona la ciencia, haceos científicos. No penséis en lo que va a ser de vosotros. Si trabajáis firme y con entusiasmo, la ciencia llenará vuestra vida” Severo Ochoa. 1905-1993. 

A Julia,

"La mejor vida no es la más larga, sino la más rica en buenas acciones"

Marie Curie. 1867-1934. 



\section{Abreviaturas}

\begin{tabular}{|c|c|}
\hline AFM & Microscopía de fuerza atómica. \\
\hline $\mathrm{cmg}$ & Concentración mínima de gelación. \\
\hline $\mathrm{CHCl} 3$ & Cloroformo. \\
\hline $\mathrm{CCl} 4$ & Tetracloruro de carbono. \\
\hline CSLM & Microscopio confocal laser de barrido. \\
\hline DRX & Difracción de rayos $\mathrm{X}$. \\
\hline DOSY & Espectroscopía de difusión. \\
\hline $\mathrm{d}$ & Doblete. \\
\hline dd & Doble doblete. \\
\hline $\mathrm{D}$ & Coeficiente de disusión. \\
\hline DMSO & Dimetilsulfóxido. \\
\hline DMEN & Medio de cultivo celular. \\
\hline Fmoc & Cloruro de 9-fluorenilmetoxicarbonilo \\
\hline$G^{\prime}$ & Módulo de almacenamiento. \\
\hline$G^{\prime}$ & Módulo de pérdidas. \\
\hline HEK293 & Células embrionarias de riñón humano. \\
\hline HPLC & Cromatografía líquida de alta eficacia. \\
\hline IR & Espectroscopía Infrarroja. \\
\hline LVR & Región viscoelástica lineal. \\
\hline MDI & Diisocianato de difenilmetano. \\
\hline $\mathrm{m}$ & Multiplete. \\
\hline
\end{tabular}


Efecto Overhauser nuclear.

PM Peso molecular.

PAs Péptidos anfifílicos.

PBS Disolución de fosfatos tamponada a $\mathrm{pH}=7$.

RGD Secuencia de los aminoácidos Arginina, Glicina y Ácido Aspártico.

RMN Espectroscopia de resonancia magnética nuclear.

SDS Dodecil sulfato sódico.

SEM Microscopía electrónica de barrido.

S singlete.

TEM Microscopía electrónica de transmisión.

TFA Ácido trifluoroacético.

THF Tetrahidrofurano.

$\mathrm{T} 2$

Tiempo de relajación transversal.

triplete.

UV

Ultravioleta.

Secuencia de los aminoácidos Valina, Alanina y Ácido Glutámico.

Entalpía.

Entropía.

$\lambda$

Longitud de onda.

$\eta$

Viscosidad.

$\sigma$

Esfuerzo aplicado.

Y

Deformación del material.

$\delta$

Ángulo de desfase. 


\section{1.- INTRODUCCIÓN.}

\section{1.- Geles Moleculares.}

Hace más de 80 años, Dorothy Jordon Lloyd estableció para todo tipo de geles que “...la condición de coloide, el gel, es más fácil de reconocer que definir". ${ }^{1}$ Los geles tienen un componente líquido y un componente separado en una microfase, un gelante. ${ }^{2} \mathrm{Al}$ menos una parte de las moléculas del gelante están en forma de estructura continua, una red tridimensional (3D). La red fibrilar debe ser permeable al líquido y permanente. Como resultado, el material es "parecido a sólido" en su comportamiento reológico. ${ }^{3} \mathrm{El}$ disolvente no fluye por gravedad y en las medidas reológicas, el módulo de almacenamiento $\left(G^{\prime}\right)$ debe permanecer por encima del módulo de pérdidas $\left(G^{\prime \prime}\right)$ (véase apartado 1.2 .5$)^{4}$

Los geles pueden ser clasificados de diferentes maneras dependiendo de su origen, constitución, el tipo de entrecruzamiento que crea su red tridimensional y del disolvente que lo compone (Figura 1.1). ${ }^{5}$ Cuando el agua es el medio de un gel, se denomina hidrogel, también podemos encontrarnos disolventes orgánicos que forman parte de geles, estos se llaman organogeles. En un sentido más amplio, tenemos los aerogeles o xerogeles, cuyo medio es el aire. Según su origen están por un lado los geles naturales, constituidos por polímeros no modificados o sintetizados por el hombre o macromoléculas de origen natural. Por otro lado, los geles derivados de compuestos sintéticos pueden ser divididos en base a su constitución en macromoleculares/poliméricos y moleculares. La formación de geles a partir de compuestos macromoleculares puede obtenerse por entrecruzamiento químico o interacciones físicas. 


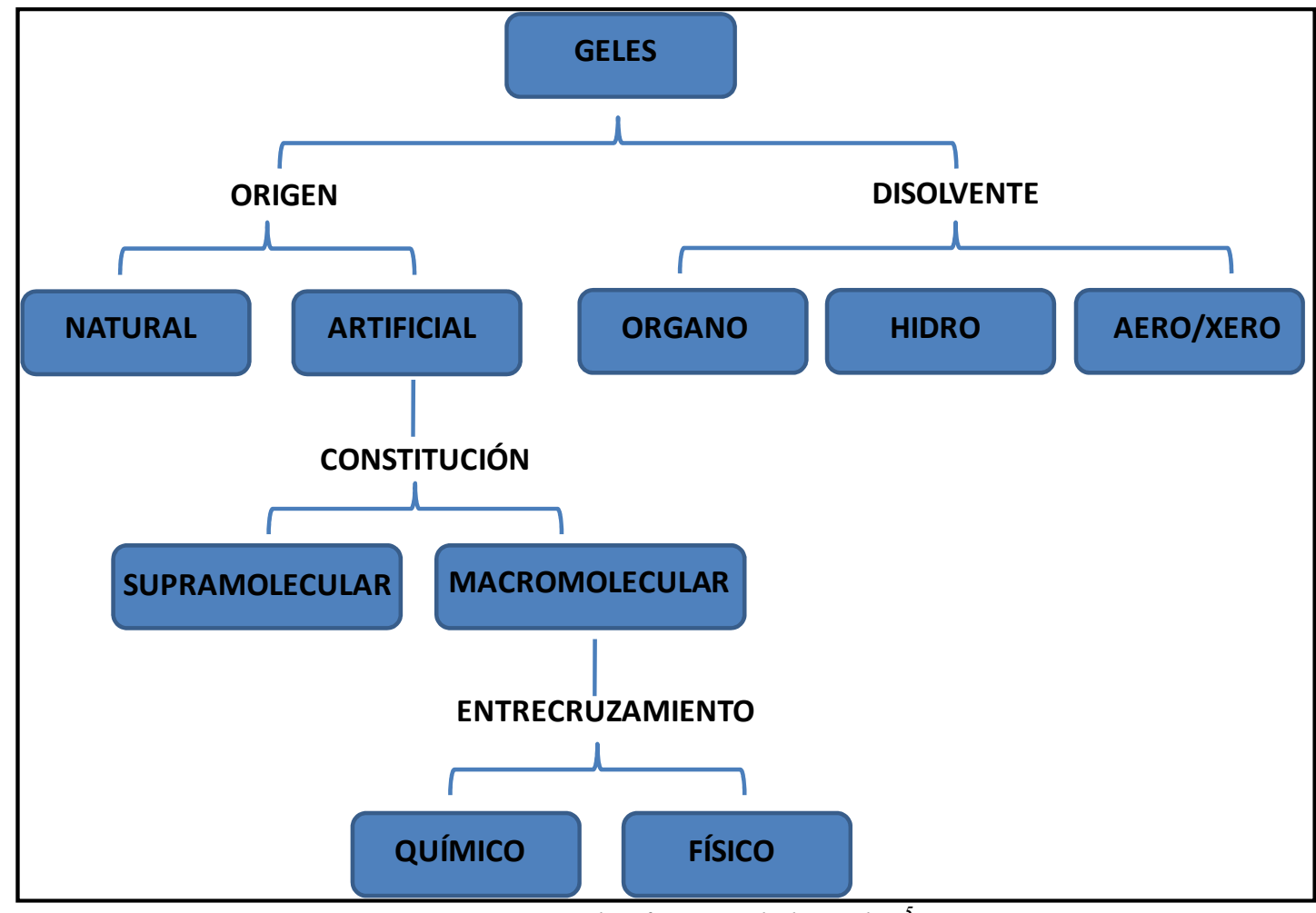

Figura 1.1: Clasificación de los geles. ${ }^{5}$

Este trabajo se centra en los geles moleculares o también denominados supramoleculares. Este calificativo es debido a que el gel no está formado por macromoléculas o polímeros sino por pequeñas moléculas de bajo peso molecular $(\mathrm{PM}<2000 \mathrm{Da})$, que dan lugar a la formación de fibras por agregación supramolecular. ${ }^{6,7}$ Los geles de bajo peso molecular se preparan normalmente por calentamiento del gelante en el disolvente apropiado y enfriando posteriormente la disolución supersaturada a temperatura ambiente. Cuando la disolución caliente se enfría, las moléculas empiezan a agregarse y son posibles tres situaciones (Figura 1.2):

(1) Una agregación altamente ordenada dando lugar al crecimiento de cristales.

(2) Una agregación aleatoria para obtener un precipitado amorfo.

(3) Un proceso de agregación intermedio entre los dos anteriores, consiguiendo un gel. ${ }^{8}$

El proceso de gelación en general consiste en la autoasociación de las moléculas de gelante para formar agregados elongados, fibrosos, similares a un polímero, los cuales se entrecruzan físicamente formando una matriz que atrapa el disolvente sobre todo por tensión superficial. En la Figura 1.3 se presenta un ejemplo de formación de gel molecular junto una imagen de la red fibrilar entrecruzada obtenida por microscopia electrónica de barrido (SEM). ${ }^{9}$ 


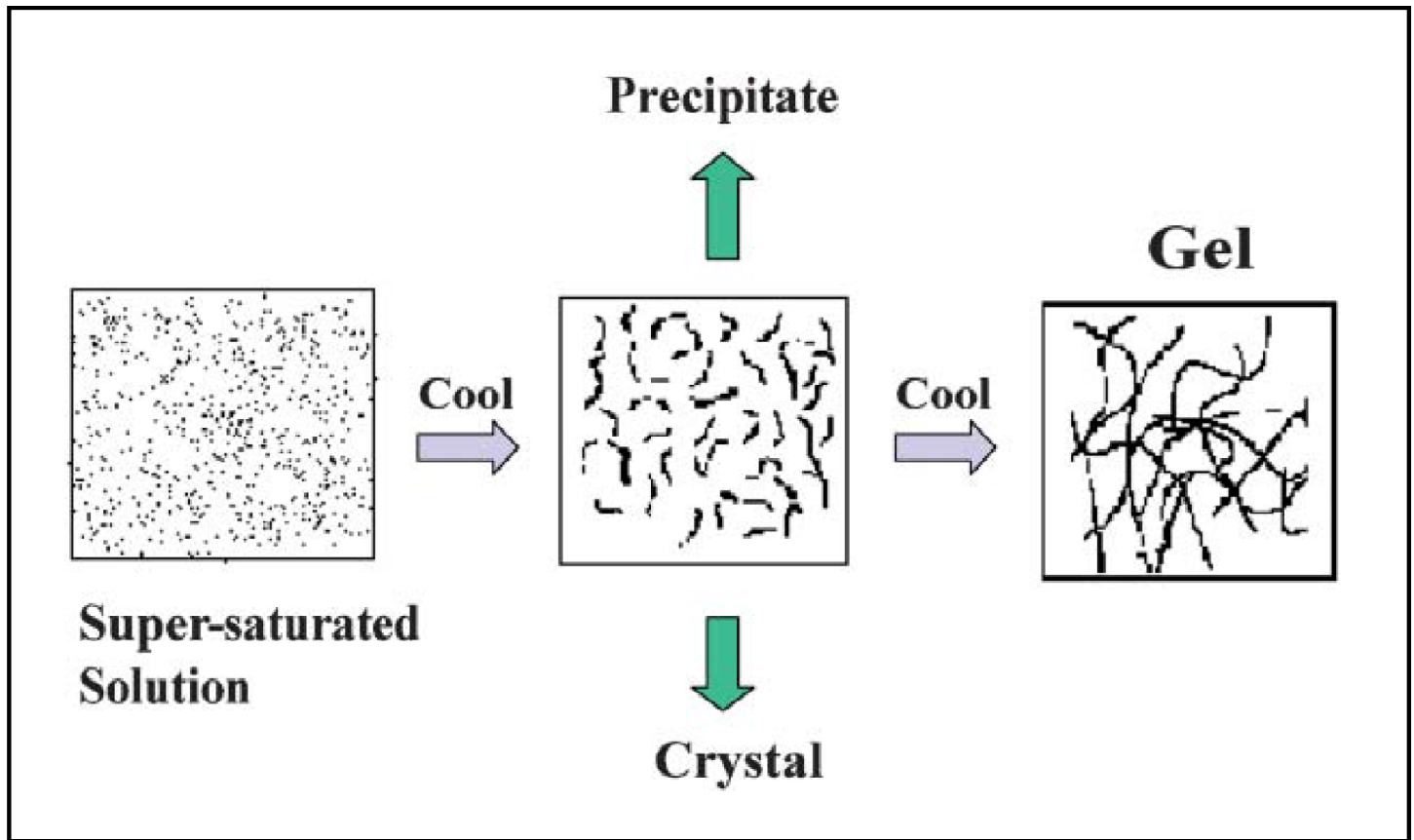

Figura 1.2: Representación de los modos de agregación. ${ }^{8}$

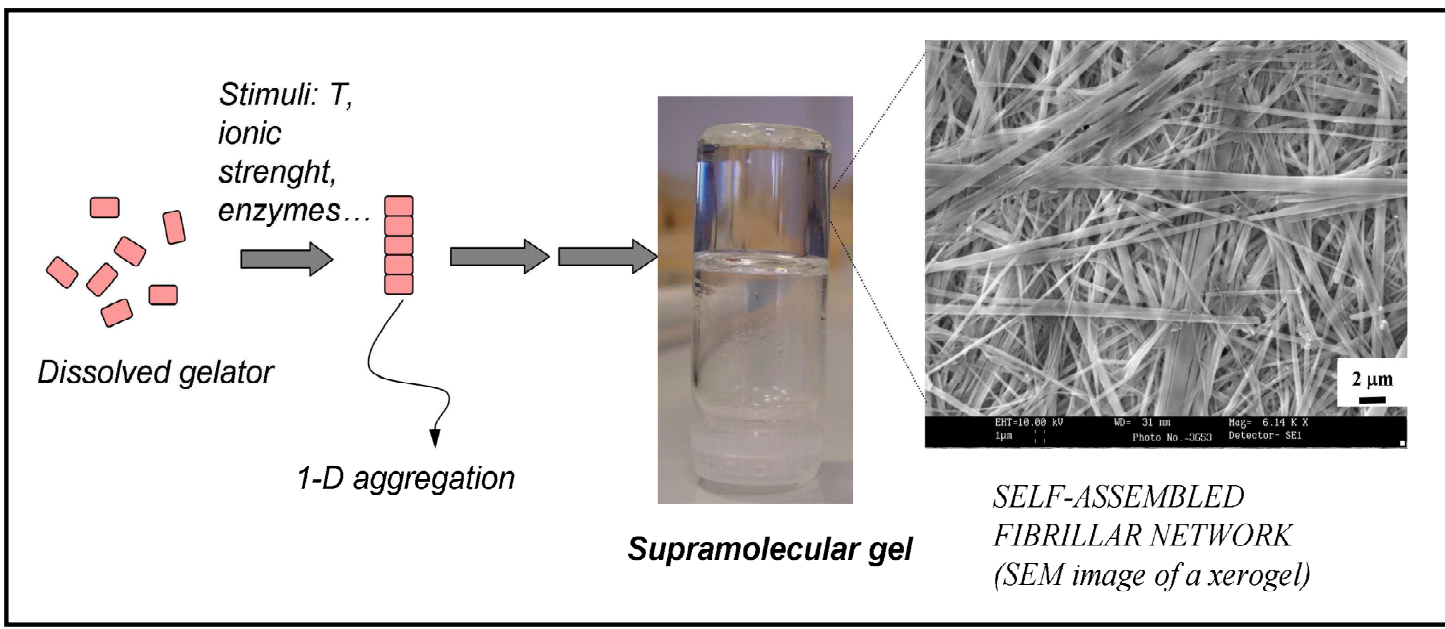

Figura 1.3: Representación esquemática del proceso de autoensamblaje que produce geles supramoleculares. ${ }^{9}$

Aunque el primer gel molecular, urato de litio en agua, ${ }^{10}$ se publicó en 1841 , ha habido muy poco progreso para entender estos materiales hasta hace poco relativamente. El número de publicaciones sobre geles moleculares ha crecido exponencialmente durante los últimos 20 años (Figura 1.4). 


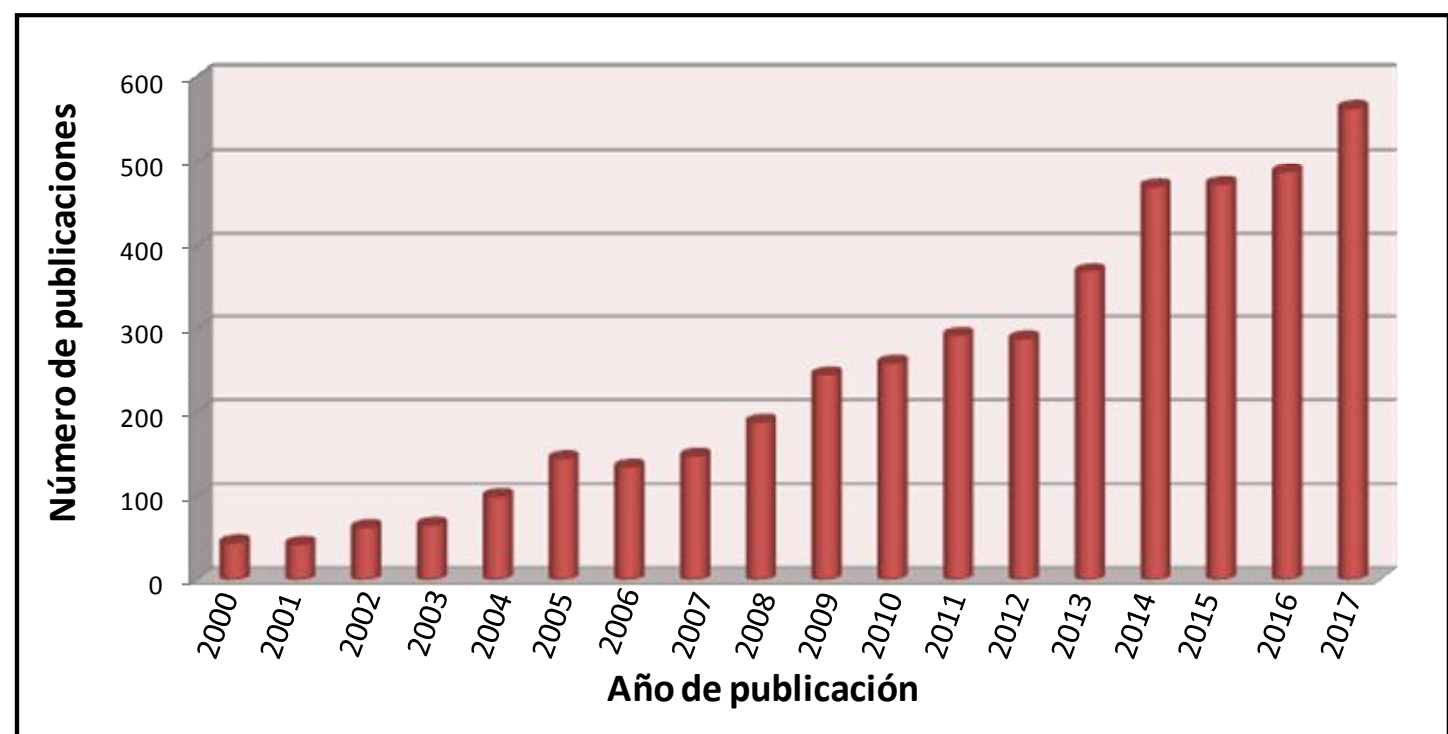

Figura 1.4: Artículos publicados que tratan de geles supramoleculares (basado en la base de datos Web of Science).

En la bibliografía existe un gran número de artículos de revisión, ${ }^{6,8,11-26}$ así como algunos libros y capítulos de libros, ${ }^{27-30}$ dedicados al estudio de geles moleculares. El reciente artículo de revisión de Weiss ${ }^{31}$ es muy aconsejable si queremos conocer el pasado, presente y futuro de los geles moleculares. Un ejemplo en el que se constata el crecimiento del interés en el campo de los geles es un artículo de revisión reciente de $\mathrm{Xu}$ et $a .^{32}$ en el que se describen más de 600 moléculas con capacidad hidrogelante.

El rango de estructuras conocidas por actuar como geles moleculares es muy amplio, abarcando moléculas muy simples como n-alcanos, ${ }^{33}$ moléculas muy pequeñas como la N,N'-dimetilurea ${ }^{34}$ y D-sorbitol ${ }^{35}$ y otras especies más complejas como por ejemplo péptidos anfifílicos. ${ }^{36}$ Pese a la gran variedad de gelantes, son comunes algunos fragmentos estructurales como azúcares, ${ }^{37}$ cadenas alquílicas, ${ }^{38}$ aminoácidos ${ }^{39}$ y péptidos, ${ }^{40}$ unidades aromáticas extendidas ${ }^{41}$ o ácidos biliares (Figura 1.5) ${ }^{42}$ 


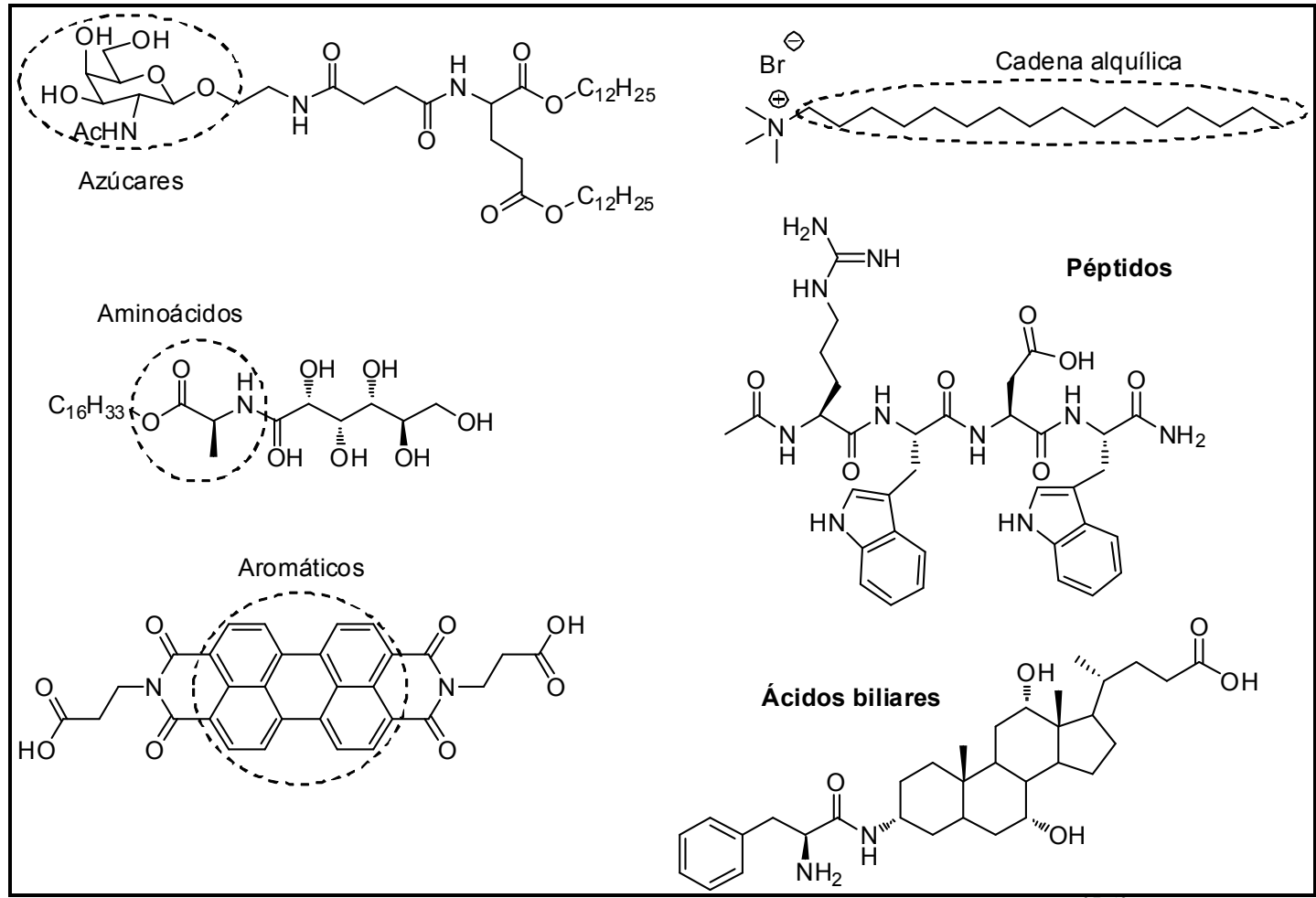

Figura 1.5: Ejemplo de la variedad estructural de geles moleculares.

En las introducciones de la mayoría de artículos sobre geles moleculares se citan numerosas posibles aplicaciones para ellos. Sin embargo, pocas de ellas se han llegado a materializar debido a diversos factores. Uno de ellos es que muchos de los geles moleculares tienen un tiempo de vida limitado a temperatura ambiente y tienen que ser mantenidos en recipientes sellados para evitar la evaporación o cambios de composición de sus componentes líquidos. En su uso en aplicaciones médicas (por ejemplo como agentes liberadores de fármacos) todos sus componentes deben ser aprobados por una agencia de salud autorizada, lo que conlleva problemas económicos y legales para su uso final. A pesar de estos obstáculos, se han descrito varios usos interesantes. Por ejemplo, un derivado dibencilado del sorbitol se ha usado para fortalecer materiales poliméricos, el compuesto retiene su red fibrilar incluso cuando se enfría a partir de polímeros fundidos. ${ }^{43}$ Se han desarrollado usos ingeniosos de enzimas para crear o destruir geles. ${ }^{44}$ También se han aplicado nuevas formas de liberación de fármacos como el caso del artículo de Majumder et al. ${ }^{45}$ En un proceso convencional de liberación de fármacos, el fármaco se introduce (física o químicamente) con una molécula portadora (usualmente un polímero), con los problemas que acarrea dicho portador (dificultad de cargar el fármaco, citotoxicidad de los materiales del portador, degradación del portador con efectos secundarios, etc.). 
En el artículo mencionado anteriormente, se consiguió aunar fármaco y portador, convirtiendo a la molécula-fármaco en un gel supramolecular (Figura 1.6). Derivados de naproxeno junto con aminas alifáticas y aromáticas, se convierten en sales que se autoensamblan como se indica en la figura, dando lugar posteriormente a un gel supramolecular. Lo más interesante de este trabajo es que se consigue un gel de aplicación tópica con una gran eficiencia probada en ratones.

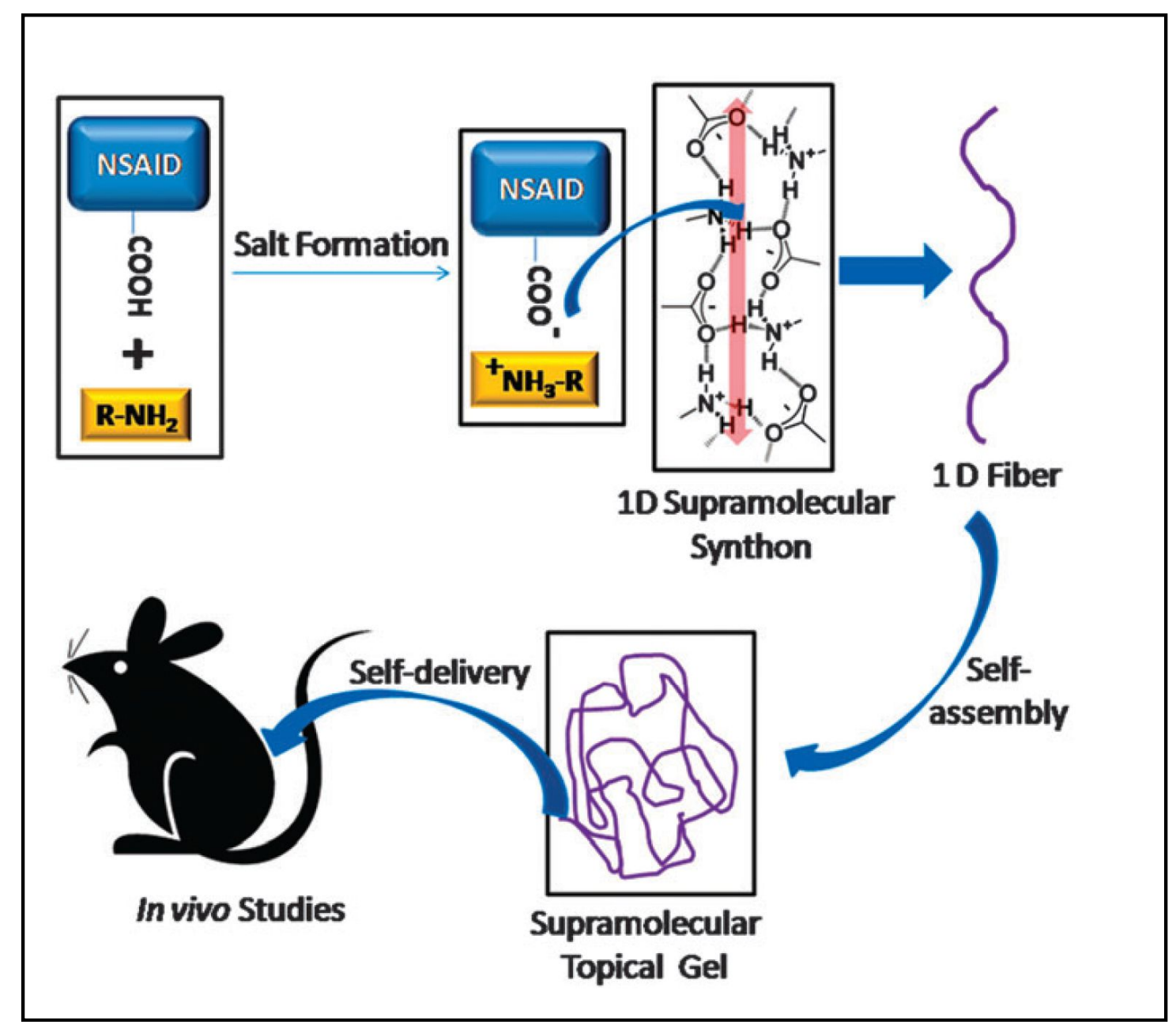

Figura 1.6: Representación esquemática del diseño de un gel molecular de aplicación tópica para aplicaciones de autoliberación de fármacos. ${ }^{45}$

Cabe indicar que en este trabajo se utiliza tanto el término gel molecular como gel supramolecular, ya que en la literatura aparecen indistintamente. Sin embargo, parece más correcto, la denominación gel molecular en oposición a gel polimérico. De hecho Weiss, un pionero en este área, tituló un libro de referencia como "geles moleculares". ${ }^{28} \mathrm{El}$ término gel supramolecular puede inducir a confusión con un gel polimérico que sufre entrecruzamiento no covalente por interacciones supramoleculares. 


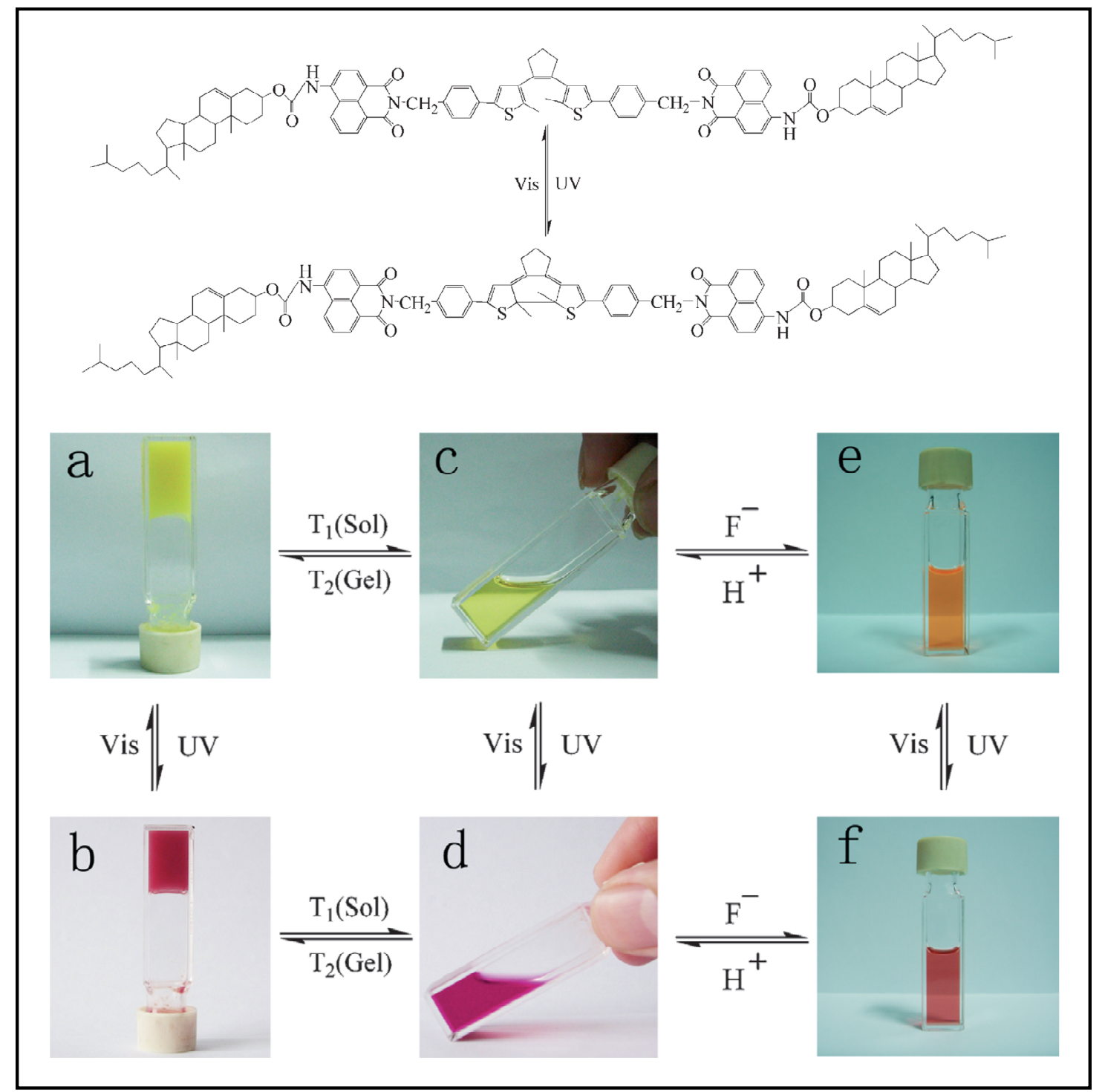

Figura 1.7: Transformación reversible de las formas abiertas y cerradas del compuesto BTE-NA-(chol) 2 y las transiciones gel-disolución bajo los efectos cooperativos de la luz, la temperatura, aniones fluoruro y protones ácidos: (a) gel (abierto); (b) gel (cerrado); (c) disolución (abierto); (d) disolución (cerrado); (e) disolución (abierto) $+F ;(f)$ disolución (cerrado) $+F^{4}{ }^{46}$

Los geles moleculares pueden ser considerados como materiales inteligentes que son capaces de responder a estímulos externos. En el artículo de revisión de Yang et al. ${ }^{47}$ se describen diferentes estímulos que provocan la formación de geles. Uno de los ejemplos citados es el trabajo de Wang et al. $^{46}$ en el que un compuesto formado por unidades de naftalimida, colesterol y tiofeno reacciona con la luz para formar o abrir un ciclo. Como se puede observar (Figura 1.7) después de la irradiación, primero con luz UV (365 nm) después con luz visible $(\lambda>510 \mathrm{~nm})$, el color amarillo (a) de la forma abierta del BTE$\mathrm{NA}-(\mathrm{chol})_{2}$ se puede convertir al color rojo (b) que corresponde a la forma cerrada del anillo como gel o disolución (d). La conversión entre fase gel y la disolución se realiza fácilmente con el estímulo térmico. Además, las disoluciones de BTE-NA-(chol $)_{2}$ ya sea 
en la forma abierta (d) o cerrada (c) de anillo son sensibles al ión fluoruro, lo que conduce a cambios en el espectro de absorción y fluorescencia. Se puede realizar el paso contrario con la adición de protón acido, con lo que se consigue la reversibilidad del proceso con estímulo químico. En resumen, este compuesto ejemplifica un sistema reversible gracias a cuatro diferentes estímulos: luz, calor, iones fluoruro y protones.

Siguiendo con el artículo de revisión de Yang et al., ${ }^{47}$ uno de los ejemplos que describen como estímulo para la formación de un gel molecular es el uso de agentes redox. En el artículo de Wang et al. ${ }^{48}$ se describe como un gelante formado por colesterol, tetratiofulvaleno (TTF) y azobenceno, puede formar geles en respuesta a estímulos redox (Figura 1.8). La adición del agente oxidante $\mathrm{Fe}^{+3}$ provoca la pérdida de un electrón del grupo electroactivo TTF para dar el correspondiente radical positivo $\left(\mathrm{TTF}^{+}\right)$provocando una ruptura del gel. Este proceso se puede revertir al añadir un agente reductor, como es el ácido ascórbico, que devuelve el electrón al grupo electroactivo y vuelve a formar el TTF inicial, que tras calentamiento y enfriamiento posterior conduce al gel inicial.

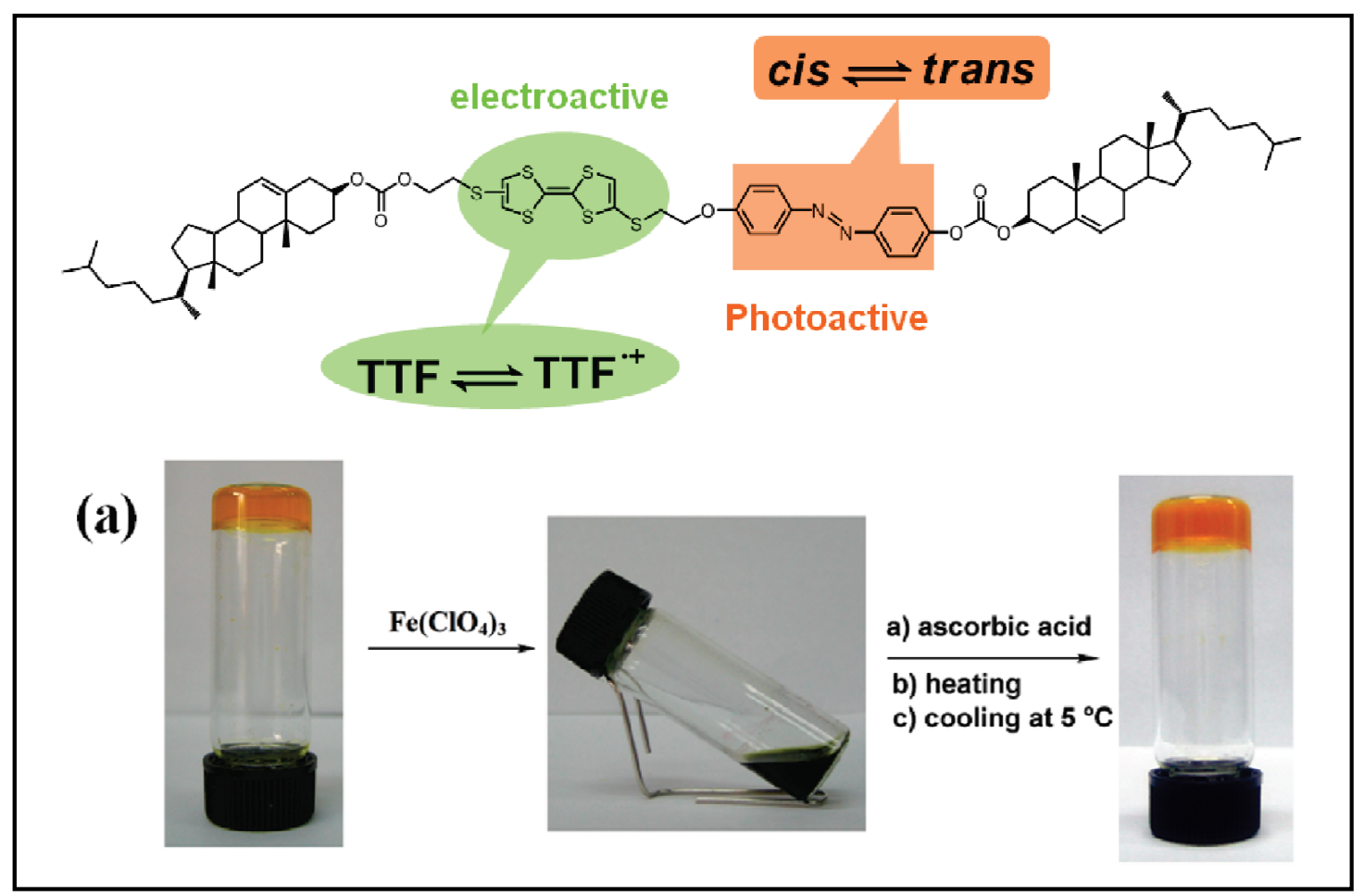

Figura 1.8: (arriba) Estructura química del gelante formado por colesterol, tetratiofulvaleno (TTF) como grupo redox y azobenceno como grupo fotónico. (abajo) Modificación de la formación del gel $(8.0 \mathrm{mg} / \mathrm{mL})$ en $\mathrm{CH}_{2} \mathrm{Cl}_{2} / \mathrm{CH}_{3} \mathrm{OH}(3 / 1, v / v)\left(\right.$ a) por oxidación y posterior reducción química. ${ }^{48}$ 
El número de aplicaciones presentes y potenciales que presentan los geles moleculares es muy extenso. En el artículo de revisión de Weiss ${ }^{31}$ se plantean posibles retos para sus futuras aplicaciones en diferentes ámbitos. Todas estas propuestas se resumen en la Tabla 1.1 .

Tabla 1.1: Futuras aplicaciones de los geles moleculares, sus autores y referencias.

\begin{tabular}{|c|c|}
\hline Retos & Autor y referencia \\
\hline $\begin{array}{l}\text { Hacer geles in situ, con moléculas de gelante que no } \\
\text { son geles cuando se enfrían, mediante el uso de } \\
\text { sonicación y microondas. }\end{array}$ & $\begin{array}{l}\text { Wang et al. } \\
\text { Naota et al. } \\
\text { Higashiguchi et al. }{ }^{51}\end{array}$ \\
\hline $\begin{array}{l}\text { Formación/ruptura de geles de manera reversible o } \\
\text { irreversible por radiación UV-visible para usos } \\
\text { específicos. }\end{array}$ & $\begin{array}{l}\text { Murata et } a l^{52} \\
\text { Kumar et al. }\end{array}$ \\
\hline $\begin{array}{l}\text { Alinear las redes fibrilares con el uso de campos } \\
\text { magnéticos o eléctricos. }\end{array}$ & $\begin{array}{l}\text { Shklyarevskiy et } \text { al. }^{54} \\
\text { Choi et al. }\end{array}$ \\
\hline $\begin{array}{l}\text { Aplicación industrial de nanopartículas magnéticas, } \\
\text { centros catalíticos o cristales líquidos en el seno de } \\
\text { geles. }\end{array}$ & $\begin{array}{l}\text { Bonini et } \text { al. }^{56} \\
\text { Bachl et al } .^{57} \\
\text { Hikmet et al. }\end{array}$ \\
\hline $\begin{array}{l}\text { Uso de geles moleculares para la limpieza de vertidos } \\
\text { químicos o de petróleo. }\end{array}$ & $\begin{array}{l}\text { Bhattacharya et al. }{ }^{59} \\
\text { Jadhav et al. } \\
\text { Trivedi et } a l . .^{61}\end{array}$ \\
\hline $\begin{array}{l}\text { Uso de geles moleculares como plantilla para fabricar } \\
\text { materiales más robustos en escala industrial. }\end{array}$ & $\begin{array}{l}\text { Jung et } a l .{ }^{62} \\
\text { Das et al. }{ }^{63}\end{array}$ \\
\hline $\begin{array}{l}\text { Ampliar el uso de geles moleculares en la industria } \\
\text { de la comida. }\end{array}$ & $\begin{array}{l}\text { Hughes et al. } \\
\text { Toro-Vazquez et al. }{ }^{65}\end{array}$ \\
\hline $\begin{array}{l}\text { Posible uso de geles moleculares, sustituyendo a los } \\
\text { geles poliméricos, para la limpieza y restauración del } \\
\text { patrimonio cultural. }\end{array}$ & $\begin{array}{l}\text { Carretti et al. }{ }^{66} \\
\text { Baglioni et al }{ }^{67}\end{array}$ \\
\hline
\end{tabular}




\section{2.- Técnicas de Caracterización de Geles Moleculares.}

\subsection{1.- Concentración mínima de gelación ( $\mathrm{cmg})$.}

Una de las formas de cuantificar la capacidad de gelación de una molécula en un determinado disolvente viene dada por la concentración mínima de gelación, cmg, de manera que un gelante será tanto más eficiente cuanto menor sea la cantidad necesaria del mismo para la formación del gel. El método más común para la determinación de este valor es lo que se conoce como el método de inversión del tubo. ${ }^{28}$ El procedimiento es muy sencillo, una vez formado el gel y esperado el tiempo necesario se da la vuelta al vial, con cuidado, y si el material viscoelástico no fluye, se considera que tenemos un gel. El fundamento reológico de este método se explica más adelante dentro del apartado dedicado a la reología (1.2.5 y Figura 1.29).

\subsection{2.- Resonancia magnética nuclear (RMN).}

La resonancia magnética nuclear es una poderosa herramienta espectroscópica muy utilizada para caracterizar los geles supramoleculares. ${ }^{68-69}$ En muchos casos su uso se centra en el análisis de la variación de los diferentes desplazamientos químicos, tiempos de relajación o intensidades de las señales de RMN con la concentración, composición del disolvente o temperatura. Los datos obtenidos son útiles para determinar la naturaleza de las interacciones intermoleculares, valores críticos de concentración, valores termodinámicos asociados al proceso de gelación e incluso cambios en el movimiento de las moléculas.

Cuando se mide la intensidad de las señales, comparadas con un patrón interno, se observa que sólo un pequeño porcentaje de gelante es observable mediante RMN. Estos resultados indican que el gelante se encuentra formando parte de la red fibrilar y no es observable mediante RMN debido al enorme tamaño de las supramoléculas presentes, originando un tiempo de relajación transversal muy pequeño $\left(T_{2}\right)$ y por tanto señales muy anchas (no observables).

En nuestro grupo de investigación se investigó el comportamiento de un gel por RMN, en el artículo de Miravet et al. ${ }^{70}$ se describe un organogelante bolaanfifílico derivado de Lvalina y protegido en los extremos por grupos benciloxicarbonil (Figura 1.9). 
En la representación gráfica podemos observar que cuando la concentración total del gelante es de alrededor de $2 \mathrm{mM}$ o mayor, la concentración visible por RMN se mantiene constante sobre 0.8-0.9 mM. Éste valor sería la solubilidad del compuesto y por lo tanto es la máxima concentración alcanzable en disolución en equilibrio con la red fibrilar del gel.<smiles>CC(C)C(NC(=O)OCc1ccccc1)C(=O)NCCCNC(=O)C(NC(=O)OCc1ccccc1)C(C)C</smiles>

(organogelante)<smiles>c1ccc(Cc2ccccc2)cc1</smiles>

Difenilmetano (referencia interna)

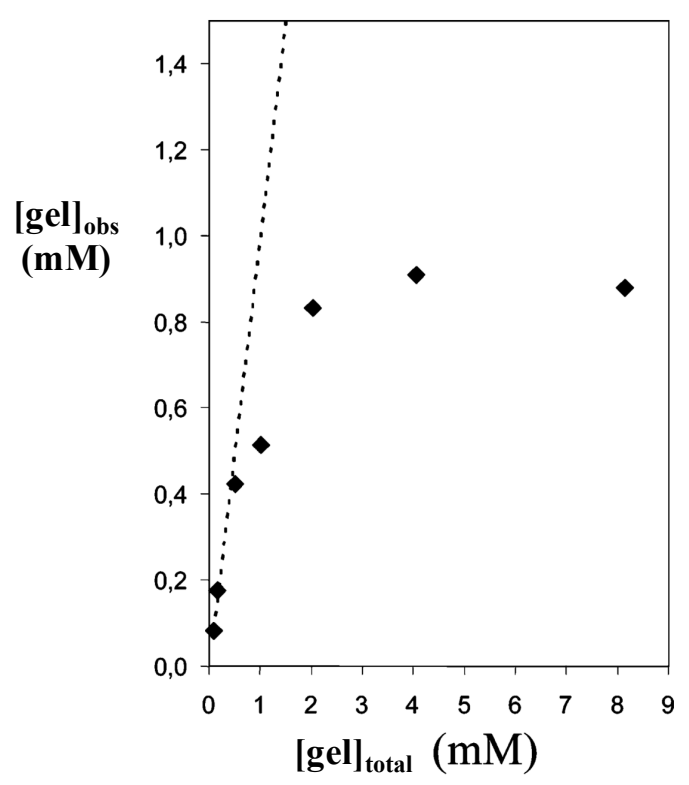

Figura 1.9: (izquierda) Estructuras del organogelante y difenilmetano usados en el estudio; (derecha) representación gráfica de la concentración del gelante en $C D_{3} C N$, medido por ${ }^{l} \mathrm{H} R M N\left(30{ }^{\circ} \mathrm{C}\right)$ usando difenilmetano como referencia interna ([gelante] ${ }_{\text {obs}}$ ), frente la concentración total presente en la muestra ([gelante] $\left.]_{\text {total}}\right)$. La línea con puntos indica el caso hipotético en el que la concentración observada fuera igual a la total. ${ }^{70}$

Por otra parte los estudios de relajación y de NOE indican que existe un intercambio rápido entre moléculas en disolución y en la red fibrilar. En el caso de los tiempos de relajación, este intercambio se manifiesta con la considerable reducción de los mismos en comparación con los medios en ausencia de gel. Por lo que respecta a los experimentos NOE, el intercambio da lugar a NOEs negativos en las moléculas de gelante como resultado de un fenómeno de transferNOE. ${ }^{71}$ 


\subsection{3.- Microscopia electrónica.}

Las técnicas electrónicas de microscopia, la de barrido (SEM) y la de transmisión (TEM) proporcionan imágenes con resoluciones del orden de $0.2 \mathrm{~nm}$, proporcionando una valiosa información sobre la morfología de los agregados que resultan de la gelación. Sin embargo, las condiciones de trabajo estándar para estas técnicas (alto vacío) requieren un completo secado de las muestras, por lo que se pueden obtener artefactos asociados a la eliminación del disolvente. Además, las técnicas de TEM y SEM requieren de un tintado para incrementar la densidad electrónica y obtener así imágenes con alta resolución, de forma que puede distorsionar la verdadera naturaleza de los agregados en el gel. Por otro lado, la microscopía de fuerza atómica (AFM) presenta la ventaja de no necesitar un sombreado metálico y proporcionar una imagen tridimensional del xerogel (gel al cual se le ha eliminado el disolvente produciendo el colapso de las fibras) manteniendo una excelente resolución. ${ }^{26,72}$

A continuación se pueden observar ejemplos del uso de estas técnicas en la literatura. En un artículo de nuestro grupo Felip et al. ${ }^{73}$ describen una transferencia de energía por solapamiento $\pi-\pi$ entre los grupos aromáticos naftalimida y acridina de los gelantes (Figura 1.10).

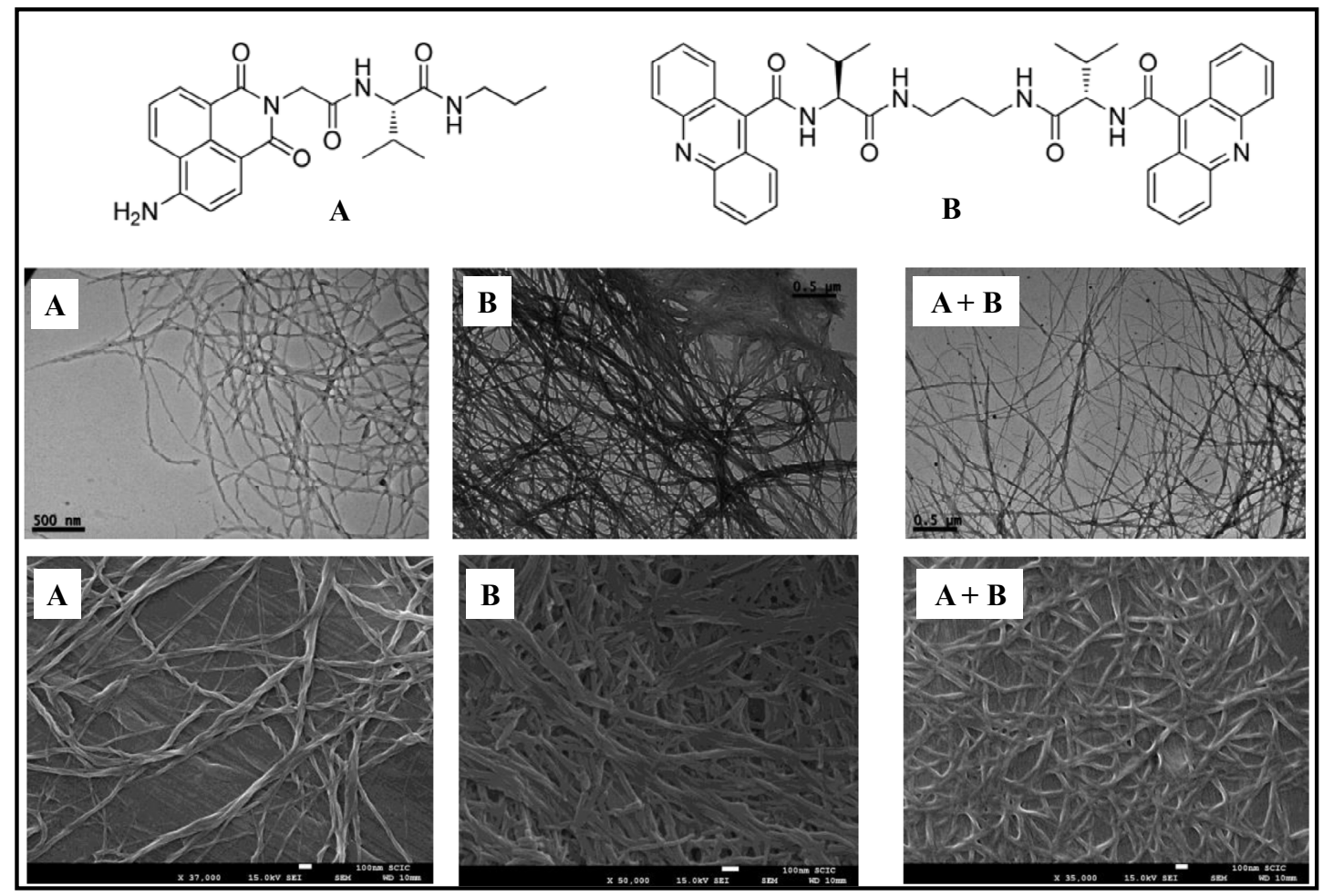

Figura 1.10:(arriba) Estructura química de los dos gelantes utilizados en el estudio; imágenes de microscopía electrónica de los xerogeles de $\boldsymbol{A}, \boldsymbol{B}$ y su mezcla. TEM y (abajo) SEM. ${ }^{73}$ 
Por otra parte, en el artículo de Singh et $a l^{74}$ se describe el uso de hidrogeles de moléculas pequeñas como potenciales portadores de doxorrubicina para descargarla in vivo. Para ello se utilizan los gelantes de alanina con carboxamida (ALA-CAM), hidracida (ALA-HYD) o la variante protonada de ésta última (ALA-HYD ${ }^{+}$). A partir de estos hidrogeles se obtuvieron las imágenes de AFM que se pueden ver en la Figura 1.11.

a)<smiles>C[C@H](NC(=O)Cc1cccc2ccccc12)C(N)=O</smiles><smiles>C[C@H](NC(=O)Cc1cccc2ccccc12)C(=O)NN</smiles><smiles>C[C@H](NC(=O)Cc1cccc2ccccc12)C(=O)N[O-]</smiles>

b)
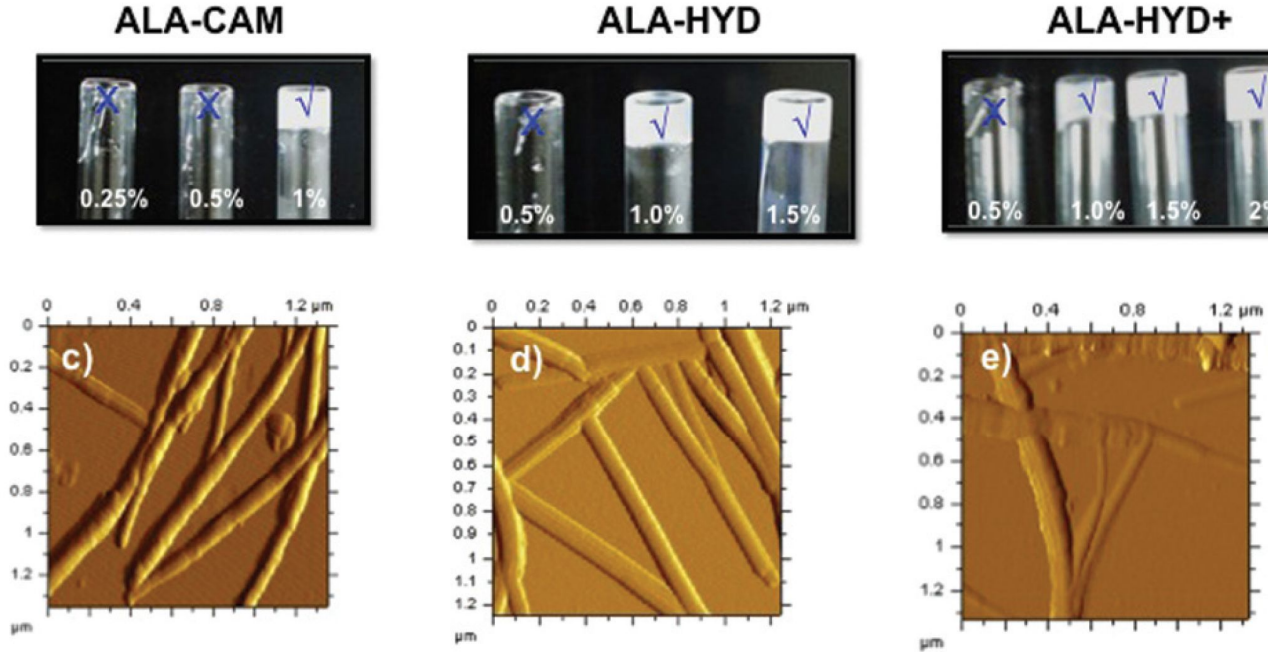

Figura 1.11: (a) Estructura molecular de los hidrogelantes, (b) imágenes de inversión de vial mostrando la capacidad de gelación de los hidrogelantes, (c-e) imágenes AFM de los hidrogeles de ALA-CAM (c), ALA$H Y D(d)$ y $A L A-H Y D^{+}(e){ }^{74}$ 


\subsection{4.- Difracción de rayos $X$.}

La difracción de rayos X (DRX) es una técnica de referencia para elucidar la estructura molecular de geles. ${ }^{75}$ Las distancias de repetición periódica obtenidas mediante esta técnica reflejan la estructura microcristalina de los xerogeles estudiados. Una de las informaciones más útiles que proporciona esta técnica es obtener el valor de $d$, que corresponde a la distancia mayor repetida en la estructura cristalina. Mediante la comparación de los valores de $d$ con el tamaño molecular se puede determinar si la conformación de la molécula del gelante en el gel se encuentra extendida o plegada. En el artículo de Jung et al. ${ }^{76}$ se describe el primer ejemplo en la literatura de un ordenamiento en bicapa basada en un hidrogel (Figura 1.12). Se puede observar cómo asignan una de las señales del espectro de difracción a la distancia de empaquetamiento entre unidades repetitivas del gel. Aunque esta técnica puede llevarnos hacia un más preciso conocimiento de empaquetado molecular entre fibras, los resultados tienen que ser tratados con cuidado ya que el proceso de secado puede originar cambios estructurales. ${ }^{77}$

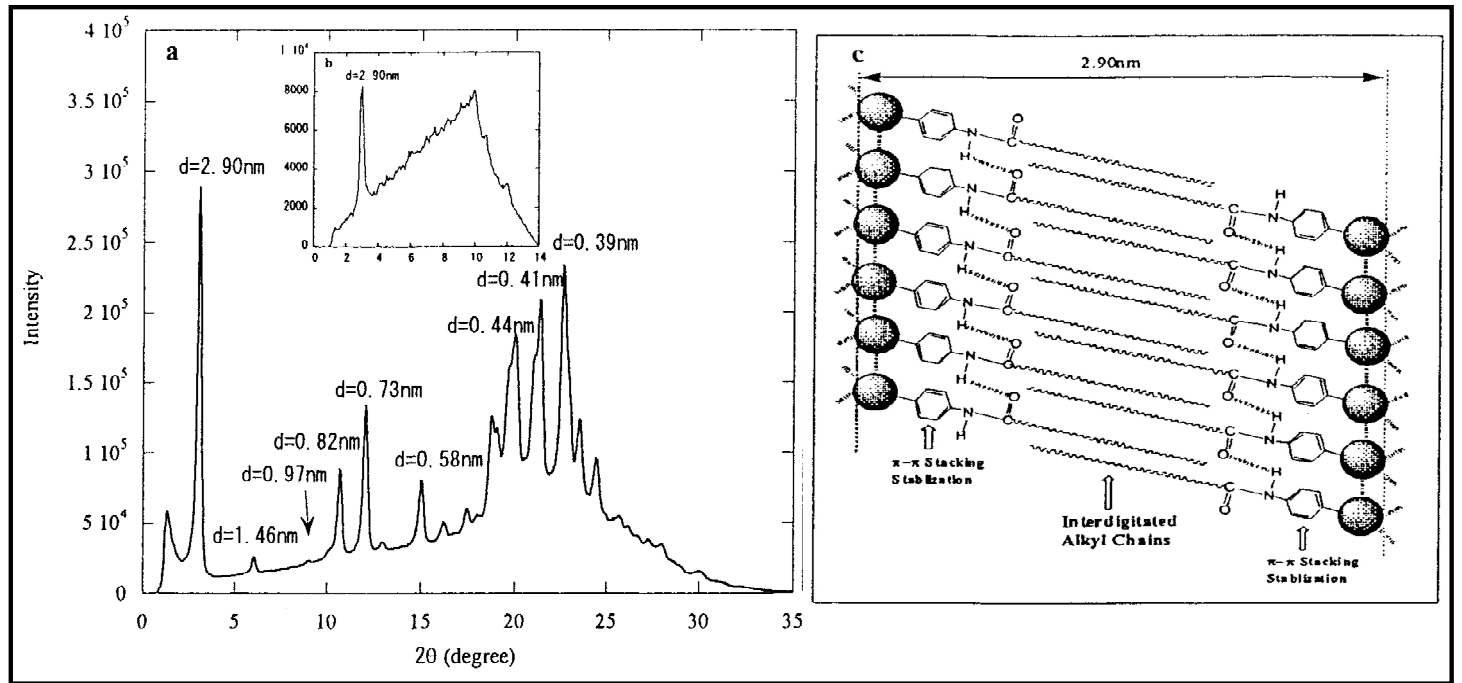

Figura 1.12: (a) Espectro de DRX en polvo de un xerogel usado para definir la distancia d de las unidades que se repiten a nivel molecular en un gelante autoensamblado. (b) Posible microestructura autoensamblada de un gel acuoso. ${ }^{76}$ 


\subsection{5.- Reología.}

La reología estudia la relación entre el esfuerzo y la deformación en los materiales que son capaces de fluir. Barnes definió flujo como "una deformación, de la cual por lo menos una parte no es recuperable". ${ }^{78}$ Por otra parte James E. Mark definió la deformación como "un cambio o variación de la forma, por lo tanto un líquido se deforma al fluir en un tubo, debido a fuerzas como por ejemplo la gravedad". ${ }^{79}$

Existen diferentes modos de deformación que se pueden aplicar a los materiales (Figura 1.13), torsión, tensión, comprensión y flexión. Para el estudio de geles nos fijaremos en el modo de deformación de cizalla que se caracteriza por transformar un rectángulo en un paralelogramo (Shear Stress, Figura 1.14). Los parámetros que hay que tener en cuenta son, entre otros, el esfuerzo aplicado, la deformación aplicada y la velocidad de deformación (Figura 1.14 parte inferior).

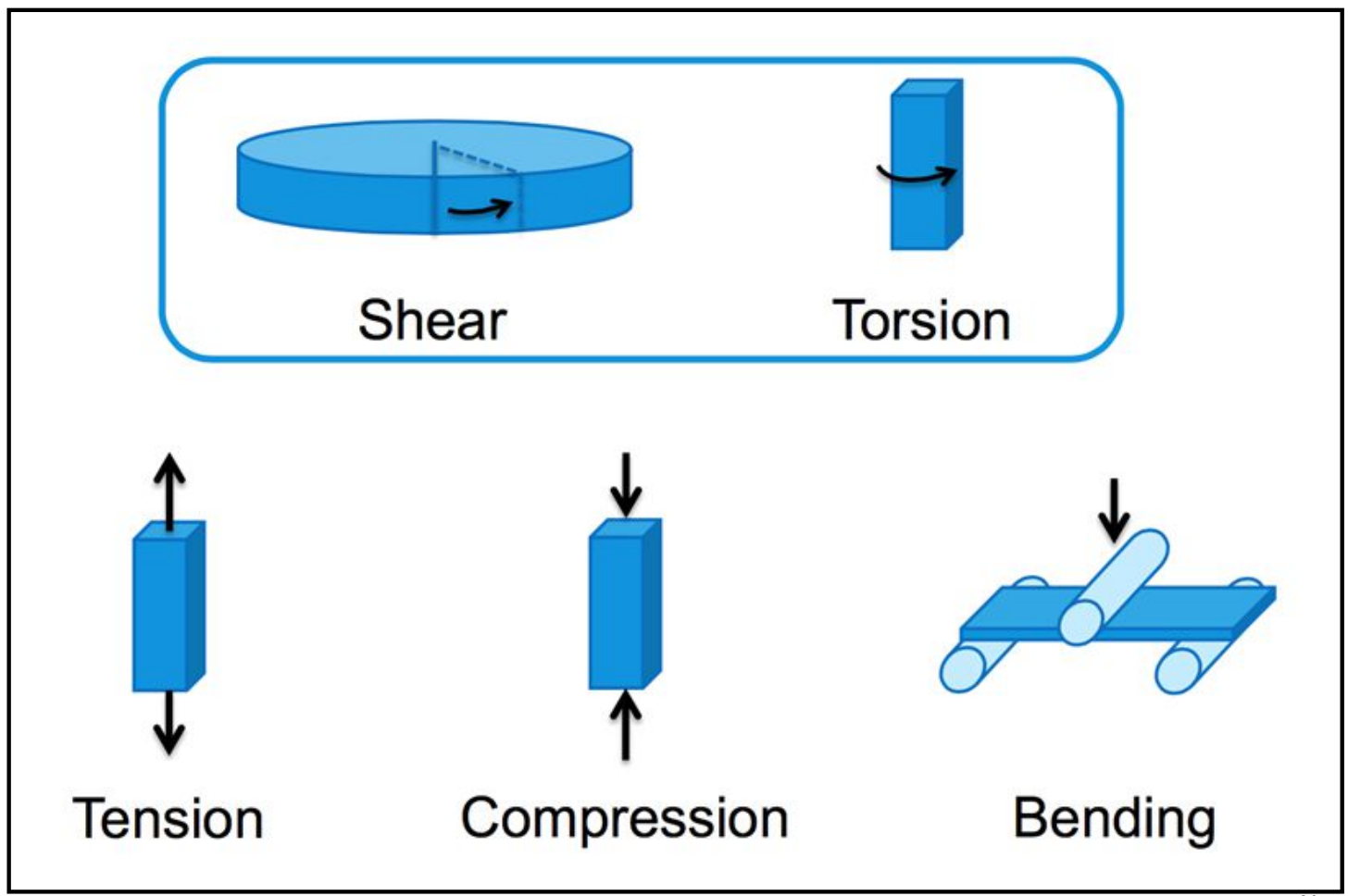

Figura 1.13: Diferentes fuerzas que se pueden aplicar sobre una muestra en un ensayo reológico. ${ }^{80}$ 


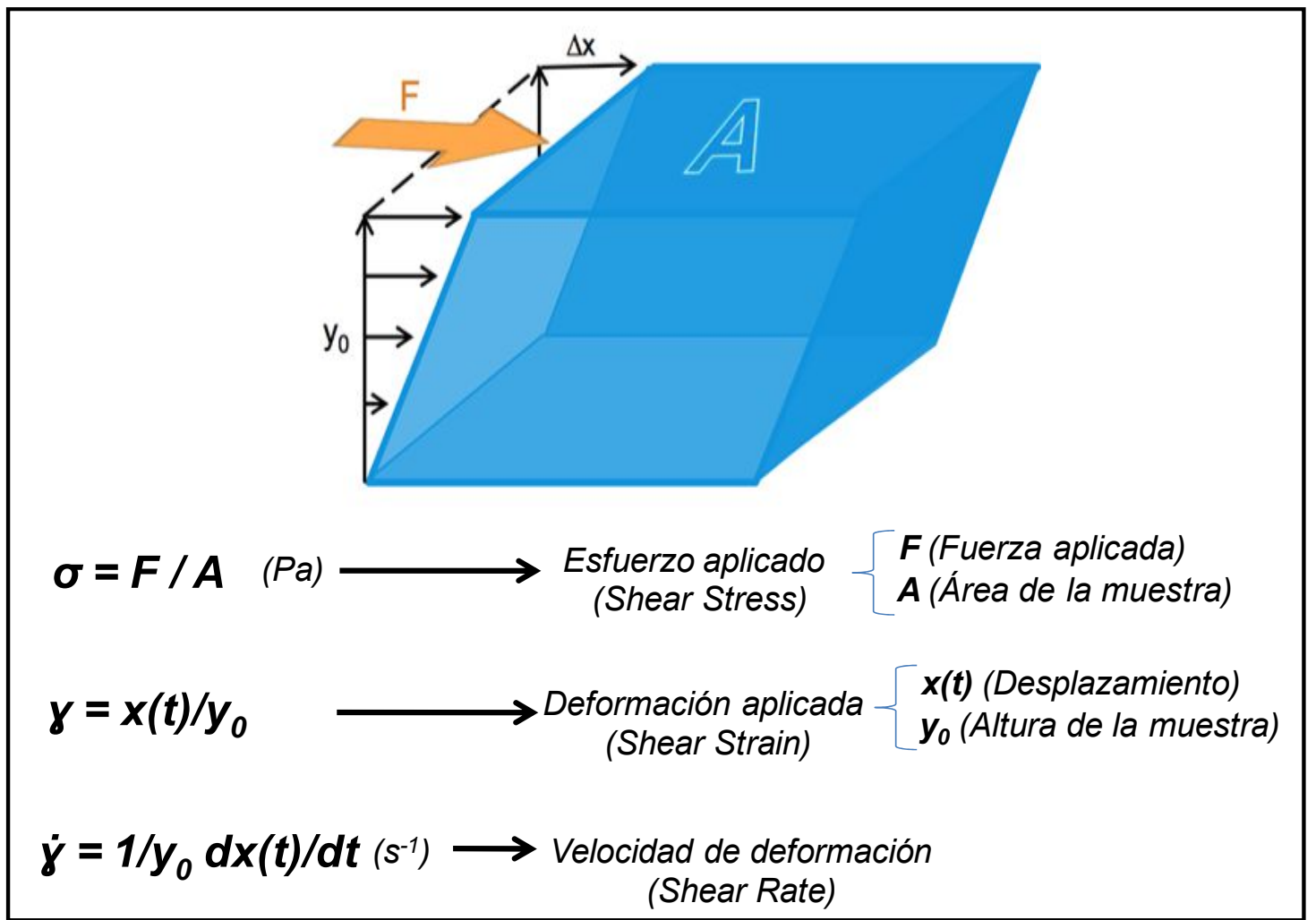

Figura 1.14: Ensayo de deformación en cizalla en la parte superior. Diferentes ecuaciones importantes a tener en cuenta en la deformación de cizalla. ${ }^{80}$

Como la reología es el estudio del flujo y deformación de los materiales, es necesario establecer los rangos de comportamientos reológicos entre los dos extremos clásicos: sólido y fluido ideal. Entre ellos existen una gran variedad de materiales con diferente comportamiento reológico (Figura 1.15). Como se puede ver en la Figura 1.16, estos extremos están definidos por las leyes de Newton (fluido ideal) y de Hooke (sólido ideal), y ambos poseen un comportamiento lineal. En los dos casos se propone una proporcionalidad directa entre esfuerzo y velocidad de deformación. Por una parte Newton habla de fluidos puros donde la viscosidad relaciona de manera lineal el esfuerzo y la velocidad de deformación. Por otra parte Hooke estudió materiales puramente sólidos obteniendo el módulo de rigidez $\mathrm{G}$, el cual relaciona de manera lineal el esfuerzo y la deformación. En los materiales líquidos que tienen un comportamiento Newtoniano, la viscosidad es independiente de la velocidad de deformación hasta un cierto punto en que se convierten en un líquidos viscoelásticos. Por otro lado, sucede algo semejante con los sólidos con un comportamiento lineal donde $G$ es constante, no depende de la deformación, hasta un punto crítico en la que se convierten en sólidos viscoelásticos con una zona de respuesta no lineal. 


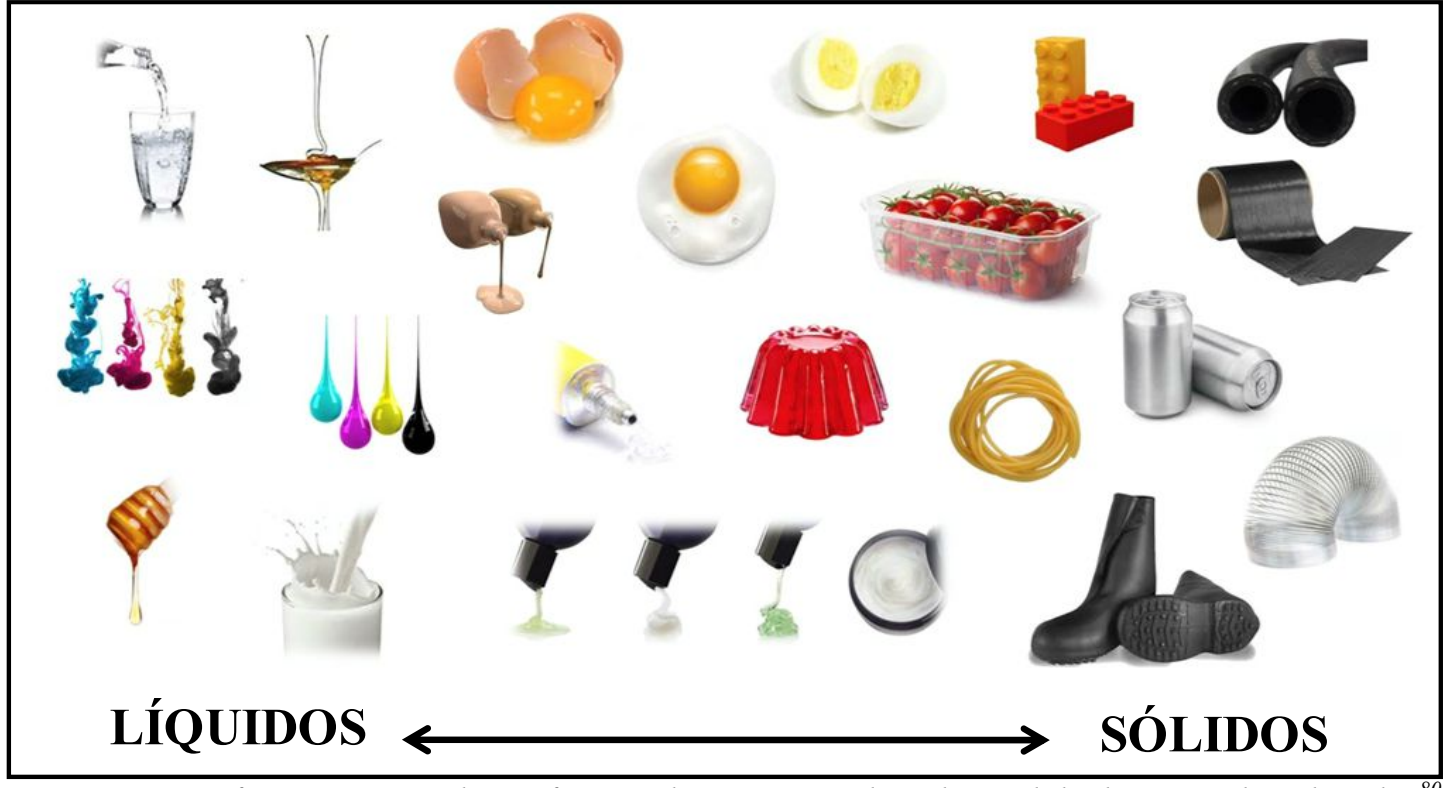

Figura 1.15: Diferentes materiales en función de su carácter líquido o sólido de izquierda a derecha. ${ }^{80}$

\begin{tabular}{|c|c|c|c|}
\hline LÍQUIDOS & \multirow{3}{*}{$\begin{array}{c}\text { Ley de Newton } \\
(1687)\end{array}$} & \multirow{4}{*}{ 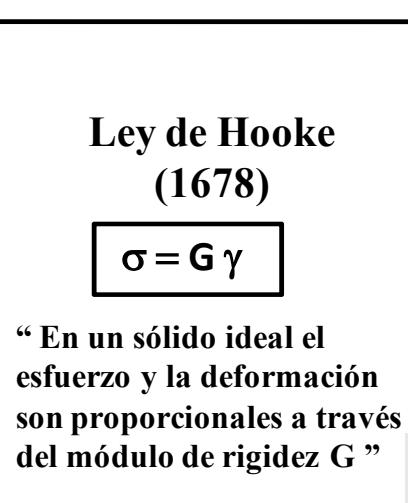 } & SÓLIDOS \\
\hline & & & \\
\hline & & & \\
\hline $\begin{array}{l}\text { Sir Isaac Newton } \\
1643-1727\end{array}$ & \multirow[t]{2}{*}{$\begin{array}{l}\text { "En un fluido ideal el } \\
\text { esfuerzo y velocidad de } \\
\text { deformación son } \\
\text { proporcionales a través } \\
\text { de la viscosidad }(\eta) \text { " }\end{array}$} & & $\begin{array}{l}\text { Robert Hooke } \\
1635-1703\end{array}$ \\
\hline $\begin{array}{l}\text { Líquido Ideal } \\
\text { "Viscosidad" }\end{array}$ & & & $\begin{array}{l}\text { Sólido Ideal } \\
\text { "Elasticidad" }\end{array}$ \\
\hline
\end{tabular}

Figura 1.16: Leyes de Newton y Hooke para un fluido o sólido ideal respectivamente.

Un parámetro importante en reología es la viscosidad. Siguiendo la ley de Newton $(\sigma=$ $\eta \cdot \gamma)$, la viscosidad es el cociente entre el esfuerzo aplicado y la velocidad de deformación $(\eta=\sigma / \gamma)$. Las unidades en el sistema internacional son Pa.s o Poise (c.g.s.), 10 Poise equivalen a 1 Pa.s.

De un modo cualitativo, se puede decir que la viscosidad mide la resistencia de un material a fluir. Como se puede observar (Tabla 1.2) la miel tiene una viscosidad 10000 veces superior a la del agua. Y el asfalto es 1 millón de veces más viscoso que el agua. Por lo que cuanto mayor es la viscosidad el material se comporta más como sólido. 
Tabla 1.2: Valores de viscosidad de distintos materiales.

\begin{tabular}{|l|r|}
\hline & \multicolumn{1}{|c|}{$\eta$ (Pa.s) } \\
\hline Asfalto & 100000 \\
\hline Polímero fundido & 1000 \\
\hline Melaza & 100 \\
\hline Miel líquida & 10 \\
\hline Glicerina & 1 \\
\hline Aceite de Oliva & 0,01 \\
\hline Agua & 0,001 \\
\hline Aire & 0,00001 \\
\hline
\end{tabular}

Mediante la observación de la viscosidad $(\eta)$ en función de la velocidad de cizalla $(\gamma)$ podemos determinar si un material tiene un comportamiento newtoniano o no. En la Figura 1.17 podemos distinguir cuatro tipos de comportamientos. Así tenemos el caso inicial de un fluido newtoniano (fluido ideal) en el cual la viscosidad no depende de la velocidad de deformación de cizalla. El siguiente sería un fluido viscoelástico, el cual presenta un comportamiento newtoniano hasta un cierto límite de velocidad de deformación en el cual la viscosidad disminuye progresivamente, este proceso se llama adelgazamiento en cizalla (Shear Thinning). Los materiales que se comportan de esta manera también son conocidos como pseudoplásticos, un ejemplo sería el kétchup, que es un fluido que se resiste a fluir en reposo pero fluye al agitar el recipiente. El siguiente ejemplo sería el aplicable a este trabajo, los geles, son materiales que se comportan como sólidos a baja velocidad de deformación, con alta viscosidad, y que al aumentar el esfuerzo sobre ellos fluyen. El último caso sería un caso especial de material que en cierto punto de velocidad de deformación en vez de bajar la viscosidad, aumenta notablemente, por lo que aumentaría su carácter sólido a grandes velocidades de deformación. Este comportamiento se denomina espesamiento de cizalla (Shear Thickening), un ejemplo de este tipo de material sería una disolución concentrada de harina de maíz que a bajas velocidades de deformación se comporta como un líquido pero si se aumenta la velocidad del esfuerzo se comporta como un sólido. 


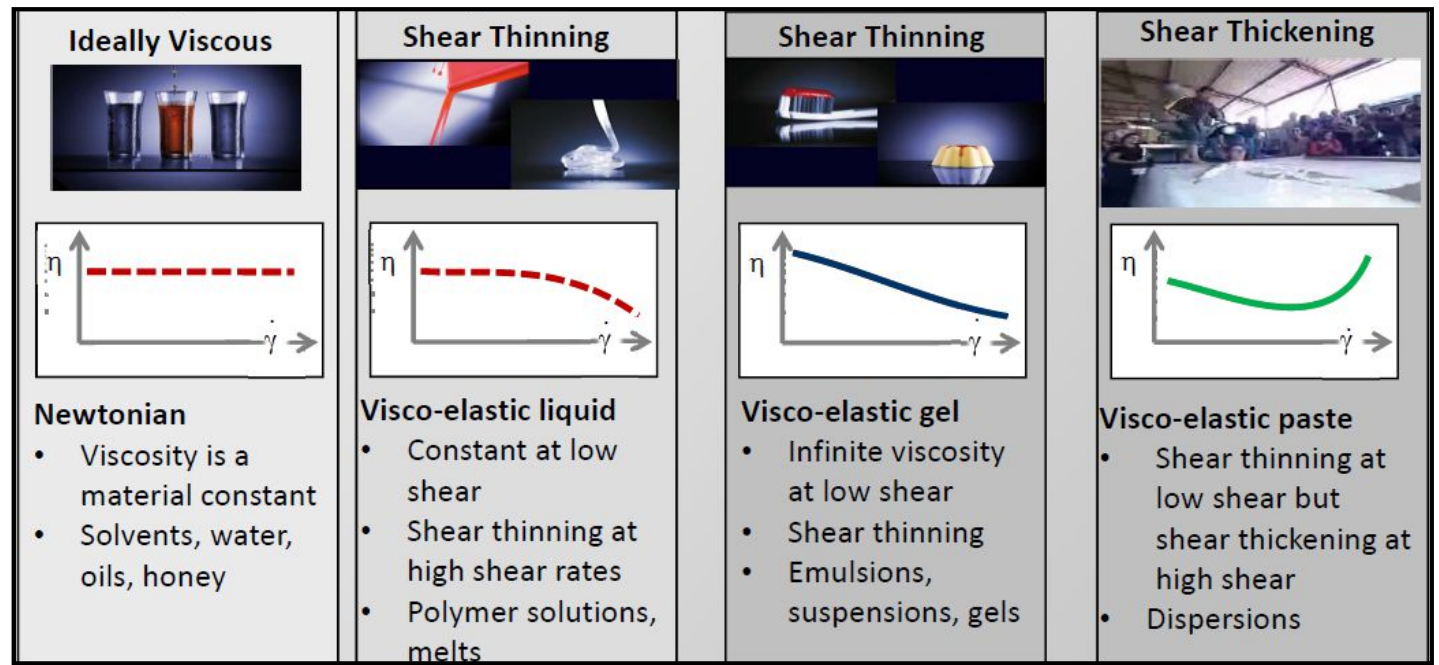

Figura 1.17: Diferentes tipos de materiales en función del comportamiento de su viscosidad en función de la velocidad de deformación de cizalla. ${ }^{80}$

Otra forma de reconocer el tipo de material reológico con el que se trabaja es representar el esfuerzo de cizalla aplicado frente a la velocidad de deformación (Figura 1.18). Debido a que la viscosidad es la tangente de las diferentes trayectorias se pueden extraer las mismas conclusiones, anteriormente comentadas, con respecto al tipo de material. De esta forma tendríamos un material newtoniano cuando la viscosidad es constante a cualquier velocidad de deformación. Por otro lado tendríamos un material pseudoplástico cuando a pequeñas velocidades se comporta como un sólido pero al aumentar la velocidad de deformación disminuye la viscosidad. $\mathrm{Y}$ finalmente tendríamos un material dilatante cuando es prácticamente un líquido $(\eta \approx 0)$ a bajas velocidades de deformación y prácticamente un sólido a altas velocidades.

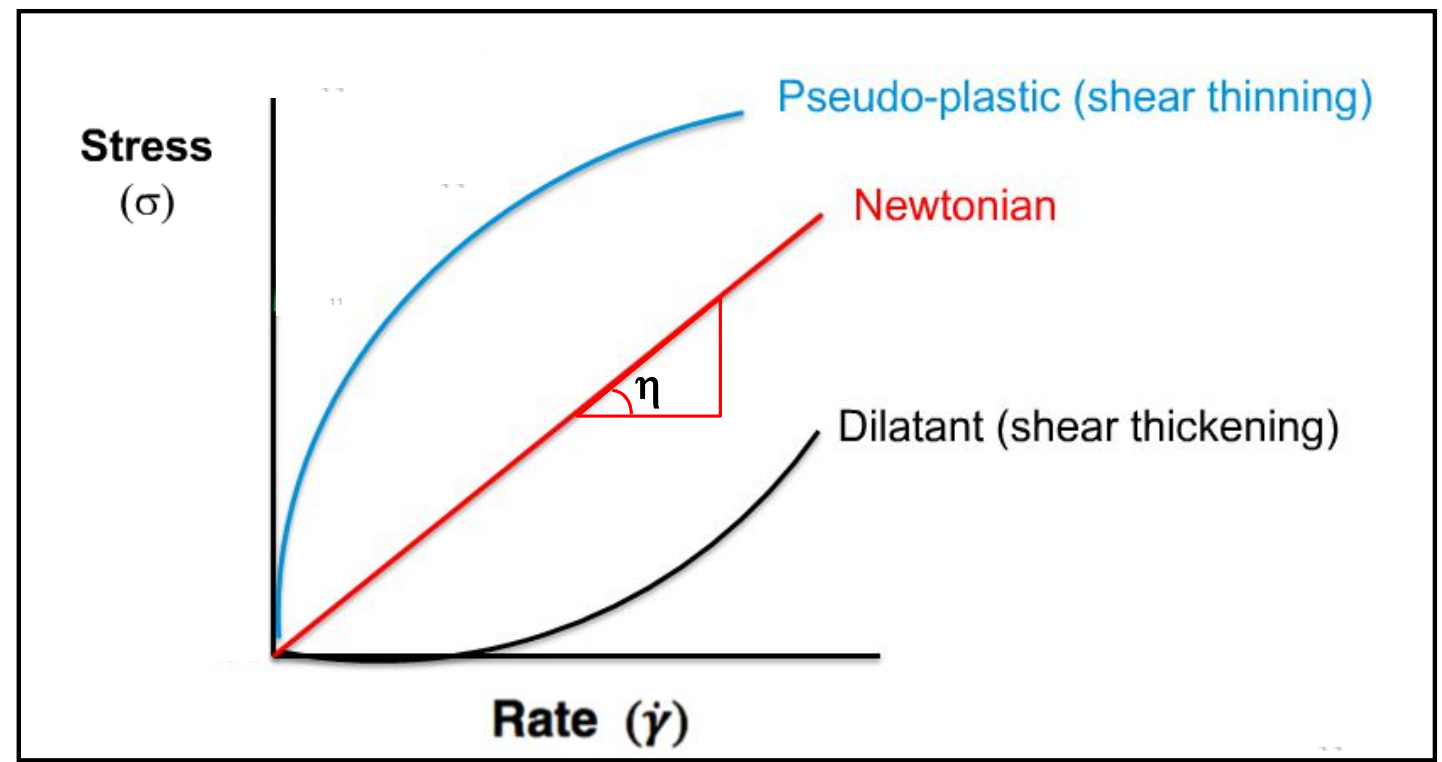

Figura 1.18: Diferentes tipos de comportamiento de los materiales en función del esfuerzo aplicado frente a la velocidad de deformación de cizalla. ${ }^{80}$ 
Para caracterizar los materiales viscoelásticos reológicamente se emplean los denominados módulos $\mathrm{G}^{\prime}$ y $\mathrm{G}^{\prime \prime}$. Estos módulos se pueden obtener por el cociente entre el esfuerzo aplicado $(\sigma)$ y la deformación del material $(\gamma)$. En la práctica con un reómetro oscilatorio estos últimos parámetros varían de manera sinusoidal (Figura 1.19), por lo que los módulos $G^{\prime}$ y $G^{\prime \prime}$ se obtienen del ángulo de desfase $(\delta)$ entre el esfuerzo y la deformación.

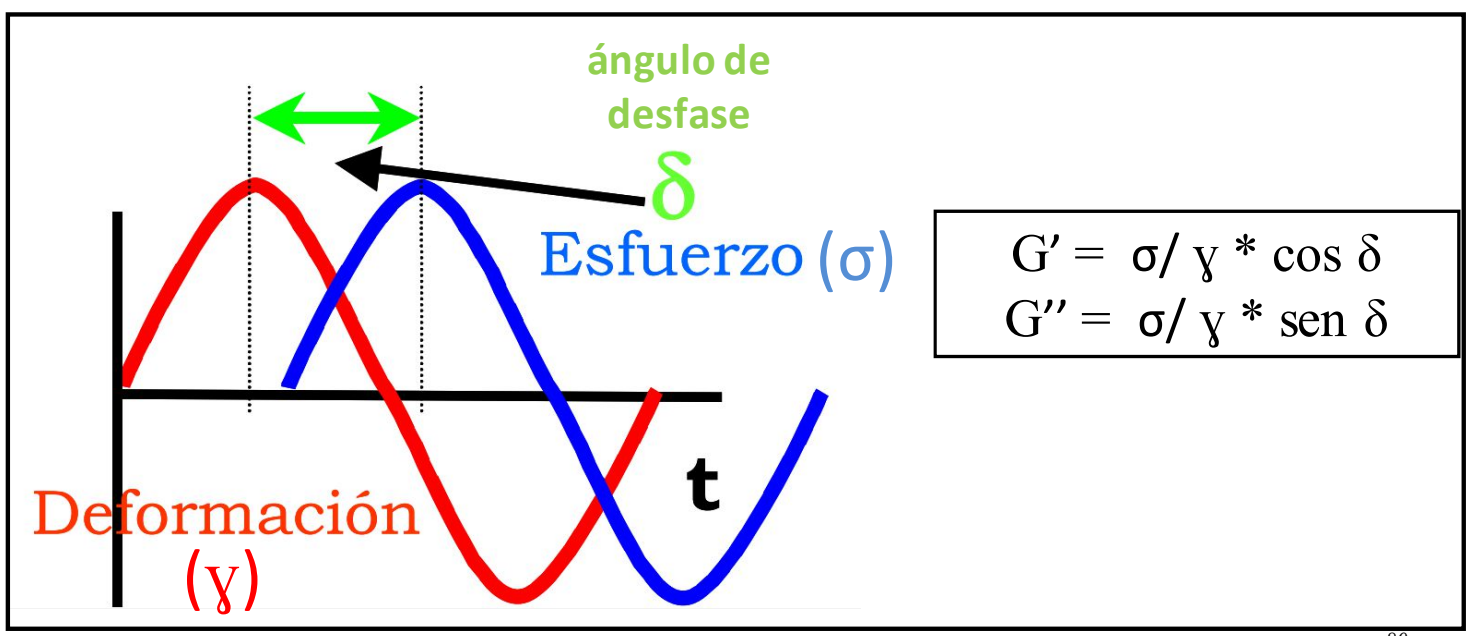

Figura 1.19: Material viscoelástico: esfuerzo, deformación y ángulo de desfase $\delta$ entre ambos. ${ }^{80}$

Por un lado tenemos el módulo $\mathrm{G}^{\prime}$, o también llamado módulo elástico (o de almacenamiento). Este parámetro mide la elasticidad del material, la capacidad del material para almacenar energía proveniente del esfuerzo aplicado. Por otro lado tenemos el módulo G", o también llamado módulo viscoso (o de pérdidas). Este mide la capacidad del material para disipar energía en forma de calor. Por lo tanto un material que tiene un alto $\mathrm{G}^{\prime}$ y un bajo $\mathrm{G}^{\prime \prime}$, es altamente elástico, más parecido a un sólido que un líquido.

La relación entre estos dos parámetros nos proporciona una nueva variable llamada $\tan \delta$ $\left(\tan \delta=\mathrm{G}^{\prime \prime} / \mathrm{G}^{\prime}\right)$ que mide la disipación de energía (Figura 1.20). A mayor valor de $\tan \delta$, se tiene un material más parecido a líquido y como caso extremo el líquido ideal, donde $G^{\prime}=0$ y por lo tanto tan $\delta$ tiene un valor infinito. Por el contrario con un $\tan \delta$ pequeño, tenemos un material más parecido a sólido y como caso extremo un sólido ideal cuando $\mathrm{G}^{\prime \prime}=0 \mathrm{y} \tan \delta=0$.

Estos extremos clásicos también se pueden indicar a partir del ángulo de desfase, atendiendo a la Figura 1.19, así tendríamos un material viscoso ideal (líquido) cuando el ángulo de desfase es $90^{\circ}(\cos 90=0$ por lo que G' es igual a cero y G'” tendría el máximo 
valor). Por el contrario tendríamos un material elástico ideal (sólido) cuando tanto la deformación como el esfuerzo están en fase, es decir el ángulo de desfase es $0^{\circ}$.

Si trasladamos toda esta información al mundo de los geles, se puede decir que tenemos un gel que se comporta más como sólido que como líquido cuando $\tan \delta<1$ y por el contrario tenemos un gel que se comporta más como líquido que como sólido cuando $\tan \delta>1$. Todo esto se puede apreciar en un experimento (Figura 1.21) de esfuerzo oscilatorio de cizalla variable a frecuencia constante. ${ }^{81}$ En él se observa cómo tenemos un gel en la parte izquierda de la figura, donde $\mathrm{G}^{\prime}>\mathrm{G}^{\prime \prime}$, por lo tanto el material viscoelástico tiene un comportamiento más parecido a sólido que a líquido. Por el contrario a partir del punto de ruptura del gel $\left(\mathrm{G}^{\prime}=\mathrm{G}^{\prime \prime}\right)$ tenemos un gel que se comporta más como líquido que como sólido que $\mathrm{G}^{\prime}<\mathrm{G}^{\prime \prime}$.

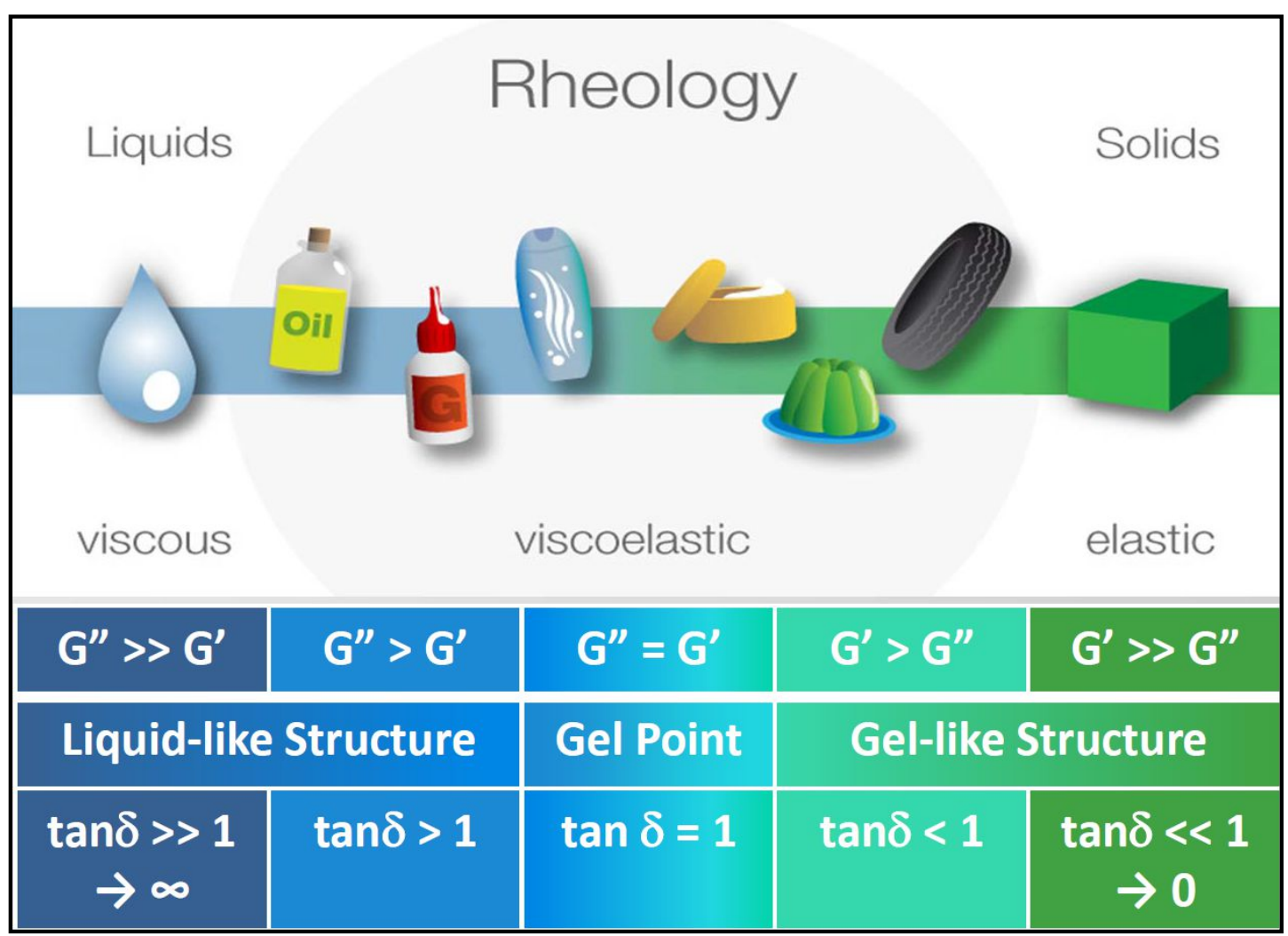

Figura 1.20: Diferentes tipos de comportamiento de los materiales en función de los valores de los parámetros viscoelásticos $G^{\prime} y G^{\prime \prime}{ }^{82}$

El siguiente punto a tener en cuenta es el tipo de reómetro a usar. Hay diversos tipos de reómetros en función del material y la medida que se busca. En el caso de los geles supramoleculares el reómetro rotacional es el utilizado comúnmente. En la figura se muestran los reómetros utilizados en este trabajo (Figura 1.22). Por un lado tenemos un reómetro Haake Mars III y un reómetro Ares AR 1000-N. 


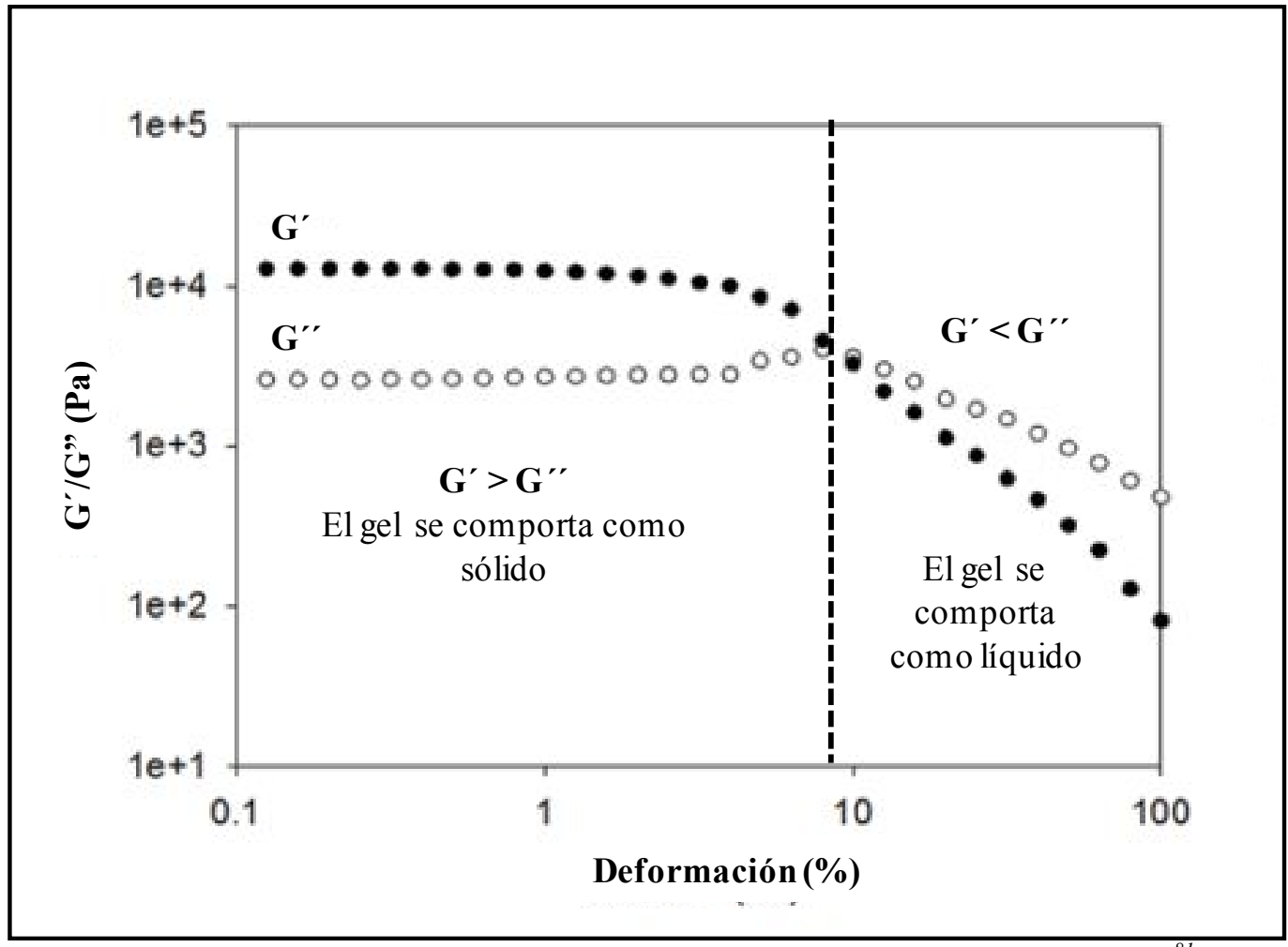

Figura 1.21: Experimento de esfuerzo oscilatorio variable a frecuencia constante. ${ }^{81}$

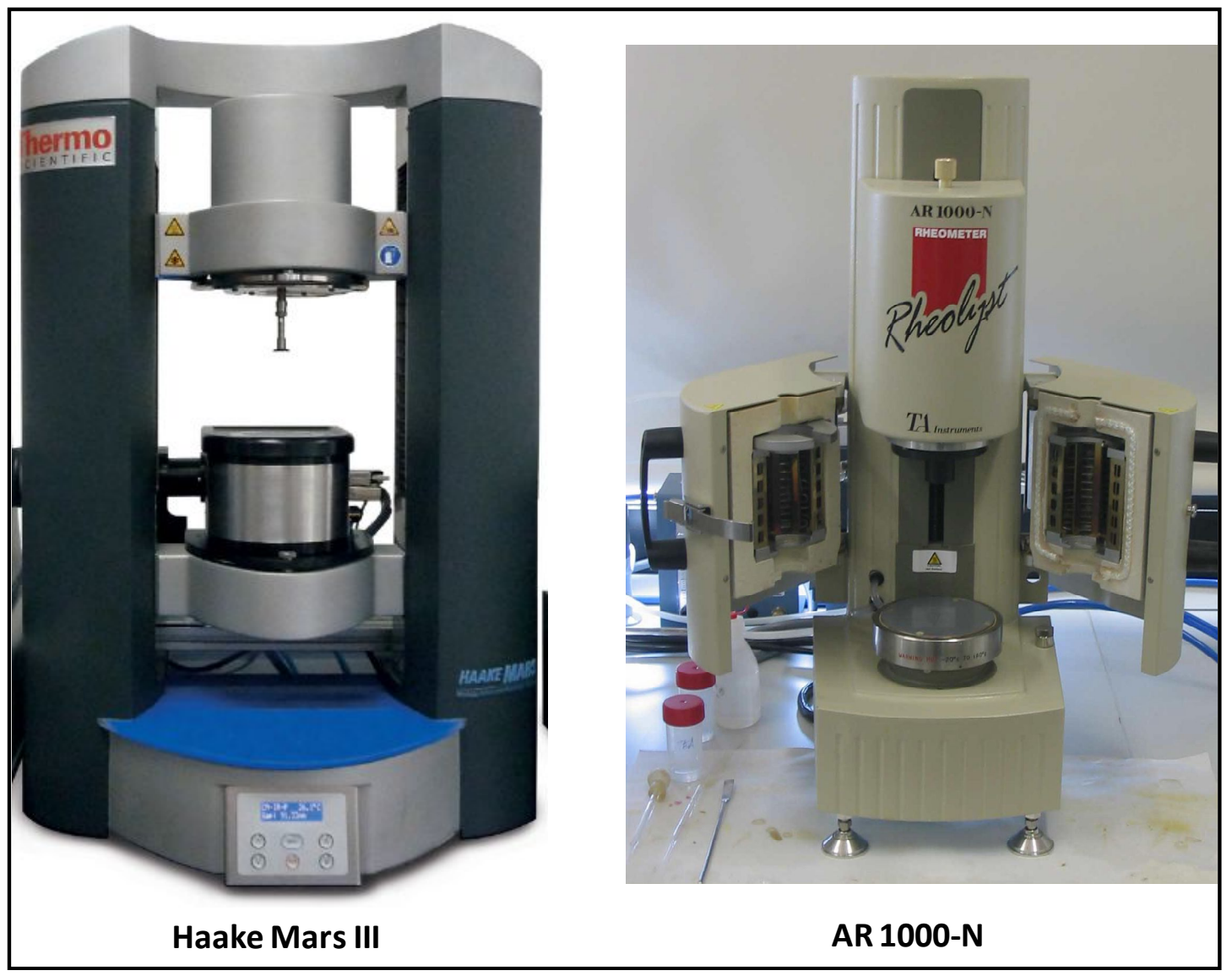

Figura 1.22: Tipos de reómetros usados durante la realización de la tesis. 
Un elemento importante a la hora de realizar medidas de reología es la forma de generar el esfuerzo de cizalla, que viene determinado por la denominada geometría del reómetro. En la Figura 1.23 se muestran las tres geometrías más habituales en los reómetros rotacionales. Por un lado tenemos los cilindros concéntricos que se usan solamente con muestras de muy baja viscosidad, prácticamente líquidas. Las otras dos geometrías, conoplato y plato paralelo, son las adecuadas para su uso con geles. Hay que tener en cuenta que el tamaño de partícula puede originar problemas con el uso del cono-plato, por lo tanto se recomienda el uso de plato paralelo cuando tengamos una muestra de tamaño de partícula grande. Es por esto que en nuestro caso se usó un plato paralelo en previsión de que el tamaño de partícula pudiera generar algún inconveniente en la medida. También es necesario decir que el tamaño del plato (Figura 1.24) puede originar inconvenientes en la medida reológica. Se decidió usar un plato de $25 \mathrm{~mm}$ de diámetro, ya que se consigue una deformación óptima de la muestra sin aplicar fuerzas muy altas (torque), además nuestros geles son de una viscosidad relativamente alta por lo que no es necesario el uso de diámetros superiores. Otro de los factores a tener en cuenta es el hueco entre plato y plato (gap) donde se deposita la muestra (Figura 1.25). Como se muestra en la figura cuanto mayor es el hueco más cantidad de muestra es necesaria y menos deformación se aplica a la muestra por ser mayor el volumen. Un punto intermedio es el que hemos escogido (gap $=1 \mathrm{~mm}$ ) para nuestro trabajo, ya que nuestro geles responden bien, reológicamente hablando.

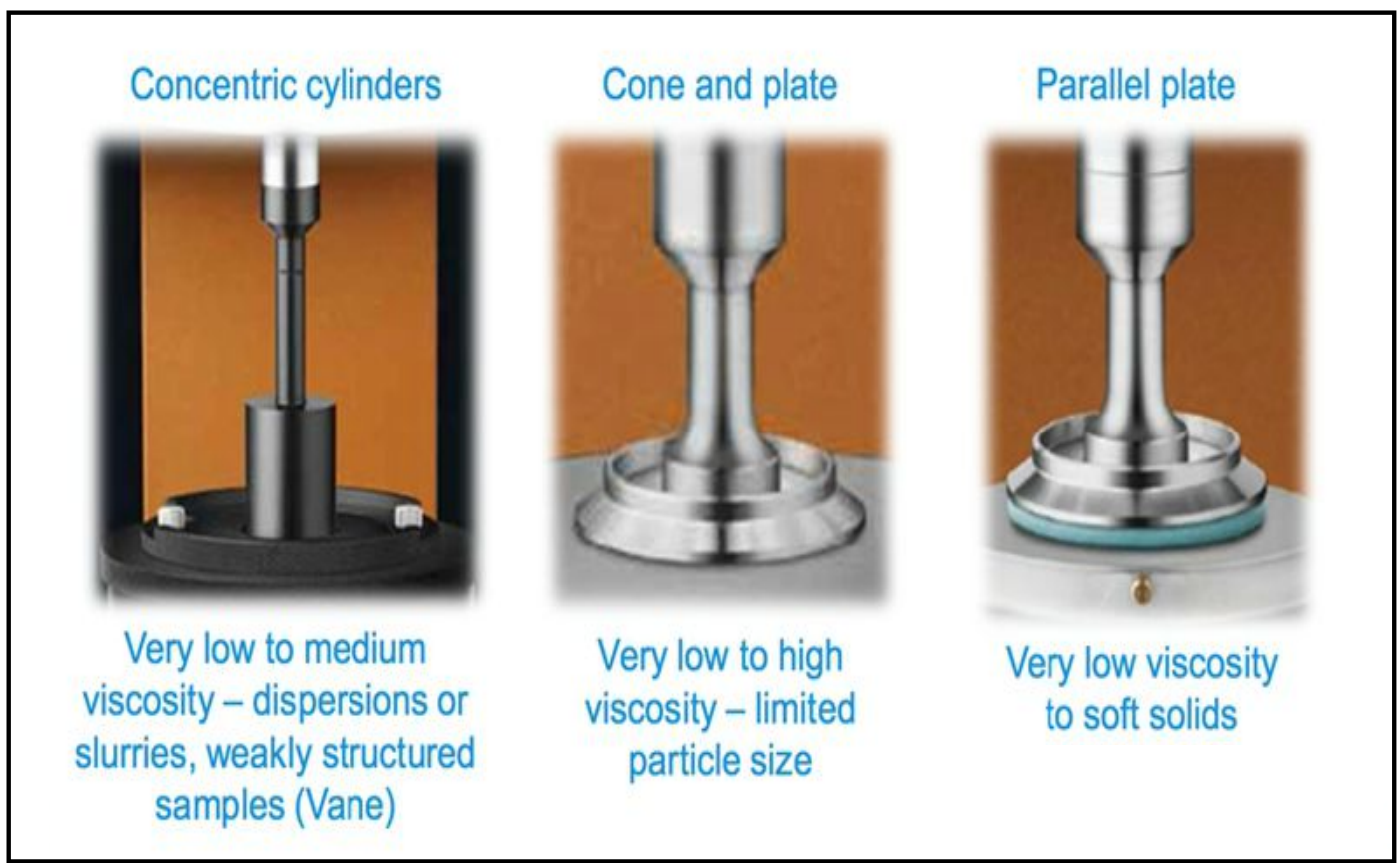

Figura 1.23: Tipos de geometrías usadas en un reómetro: de izquierda a derecha tenemos cilindros concéntricos, cono-plato y plato paralelo. ${ }^{80}$ 


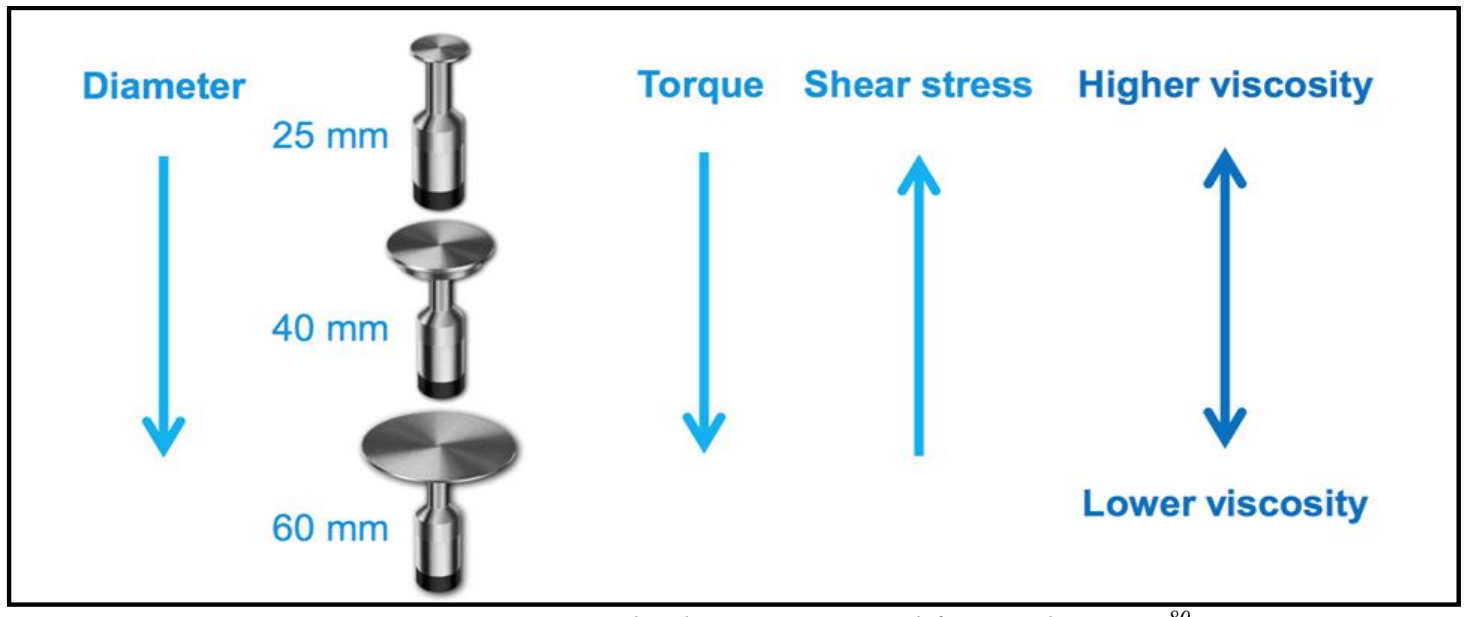

Figura 1.24: Geometría de plato o cono con diferente diámetro. ${ }^{80}$

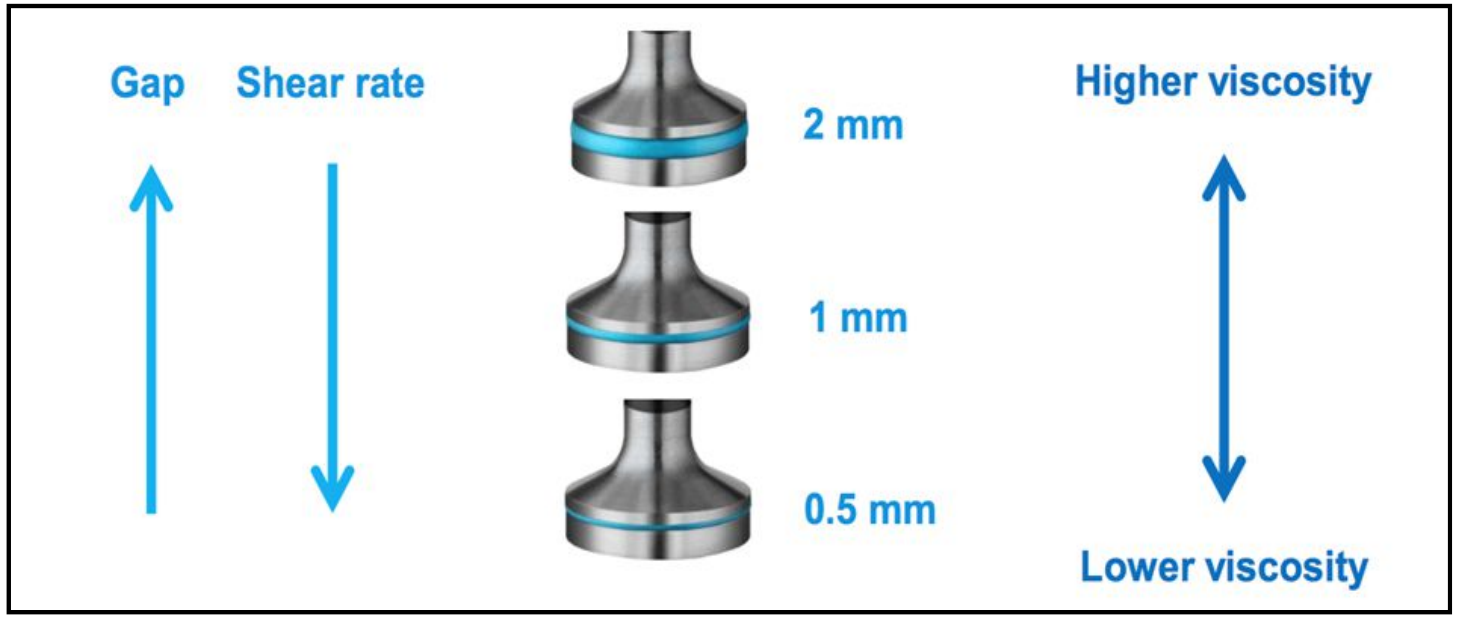

Figura 1.25: Geometrías de plato o cono con diferente hueco para la muestra (gap). ${ }^{80}$

Un aspecto importante desde el punto de vista práctico es la carga adecuada de la muestra en el reómetro para que el ensayo sea reológicamente fiable. Hay que procurar que la muestra se aproxime a la forma cóncava que se observa en la parte inferior de la Figura 1.26 . 


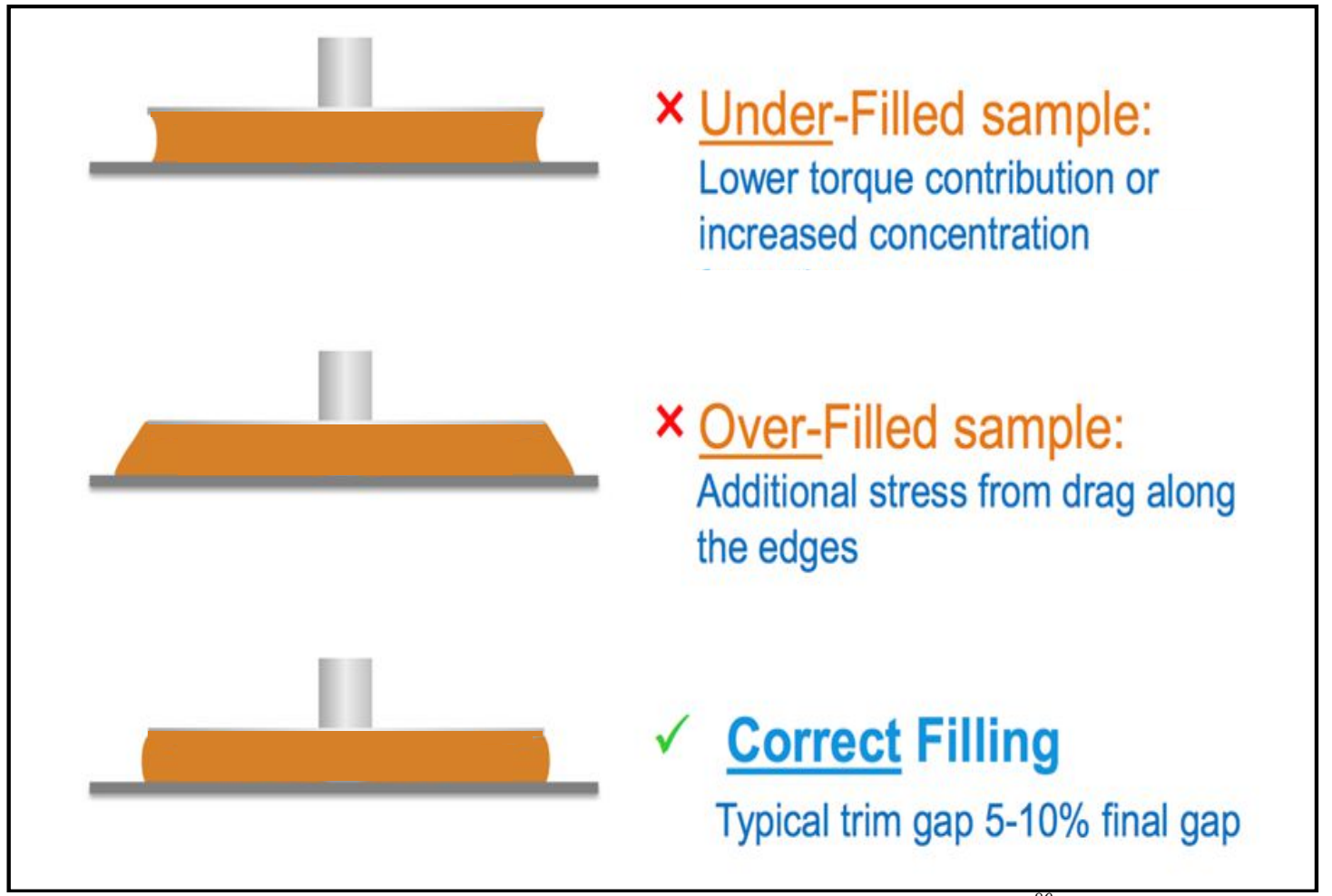

Figura 1.26: Modos de cargar una muestra en un reómetro. ${ }^{80}$

Los experimentos más comunes de caracterización de geles por reología son dos: el barrido de frecuencias a un esfuerzo de cizalla constante y el barrido de esfuerzos a frecuencia constante. La información que se extrae principalmente de ellos es la fortaleza de los geles y el grado de entrecruzamiento de las redes fibrilares. Lo primero que se necesita es que la variable usada en el experimento, ya sea el esfuerzo de cizalla o la frecuencia, tenga valores comprendidos dentro de la denominada región viscoelástica lineal (LVR), siendo esta, aquella en que la magnitud medida se mantiene constante. Por ejemplo, en el caso del barrido de esfuerzos de la Figura 1.27 la frecuencia constante elegida es $1 \mathrm{~Hz}$, debido a que este valor está en la zona en la que $\mathrm{G}^{\prime}$ no varía en función de la frecuencia (LVR), como se puede apreciar en el barrido de frecuencias de la Figura 1.27. Del mismo modo para hacer un barrido de frecuencias hay que escoger un esfuerzo de cizalla constante dentro de la zona de respuesta lineal. 


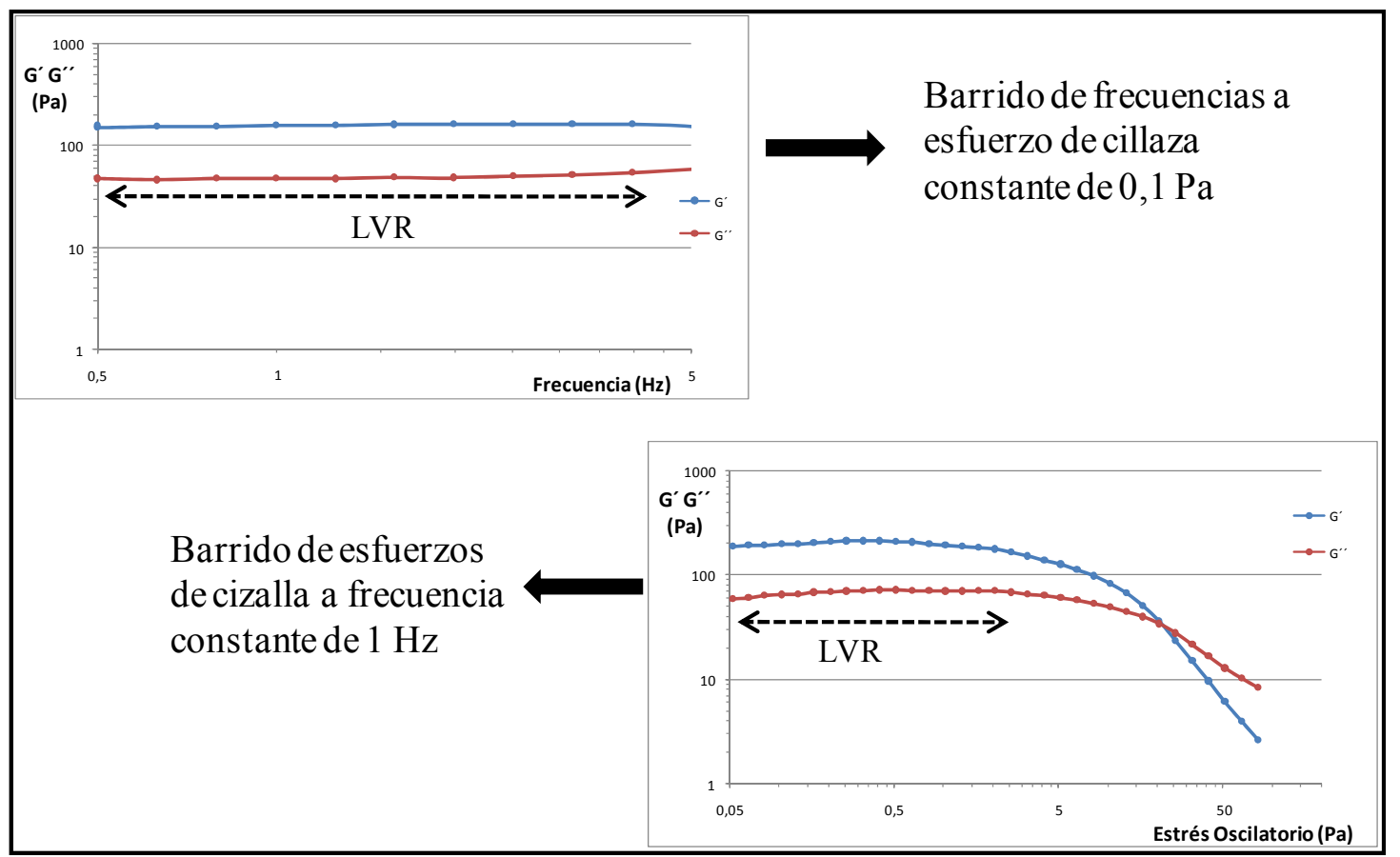

Figura 1.27: Experimentos de frecuencia variable a esfuerzo constante (arriba) y esfuerzo variable a frecuencia constante (abajo) con la región viscoelástica lineal de ambos experimentos.

En esta tesis se plantea estudiar la recuperación tixotrópica de los geles. Es por eso que es pertinente definir la tixotropía de un material viscoelástico. En un extenso artículo de revisión de Mewis y Wagner $^{83}$ se comentan diferentes aspectos de la tixotropía. El término fue introducido por Freundlich, basado en una sugerencia de T. Peterfi quien encontró que el protoplasma celular se podía hacer líquido por una acción mecánica. La palabra tixotropía se deriva de las palabras griegas $\theta i ́ \xi ı$ (thixis: agitación, sacudida) y $\tau \rho \varepsilon ́ \pi \omega$ (trepo: girando o cambiando). Hay una definición actual de tixotropía que posee un alto grado de aceptación por la comunidad científica: "tixotropía es el continuo descenso de viscosidad con el tiempo cuando se aplica un esfuerzo a una muestra que estaba en reposo inicialmente y la consecuente recuperación de la viscosidad con el tiempo cuando el esfuerzo deja de aplicarse." Los elementos esenciales de la definición que se usa actualmente son tres. Primero, está basada en la viscosidad. Segundo, implica un descenso en función del tiempo de la viscosidad inducido por el esfuerzo aplicado. Tercero, el efecto es reversible cuando el esfuerzo decrece o es eliminado. Como se puede observar (Figura 1.28), un material tixotrópico es aquel que tras ser sometido a un esfuerzo recupera su estructura original en un determinado tiempo al cesar el esfuerzo. ${ }^{84}$ 


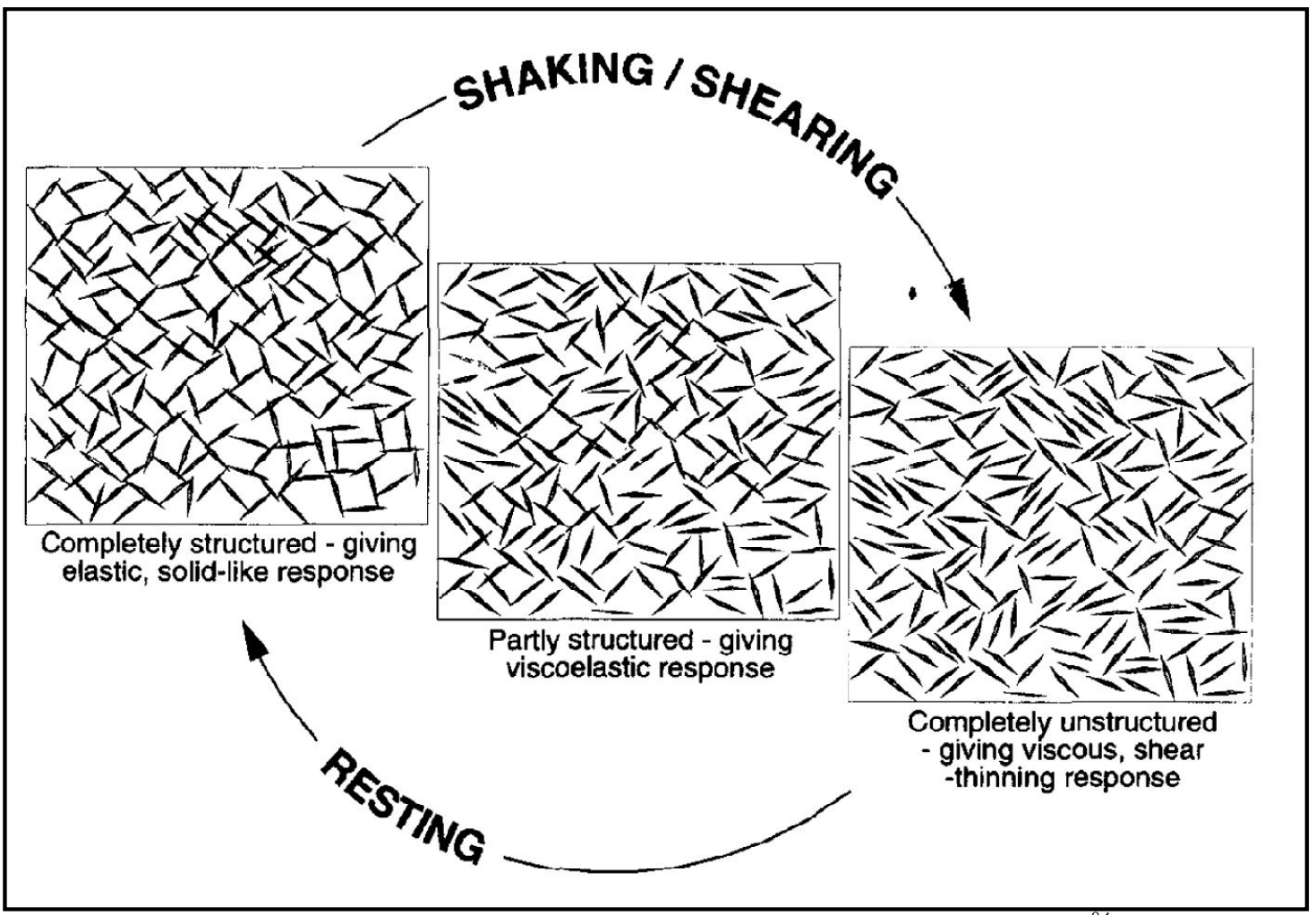

Figura 1.28: Ruptura y recuperación de una estructura $3 D$ tixotrópica. $^{84}$

En un artículo de revisión de Weiss et al. ${ }^{85}$ se recogen las correlaciones que existen entre las propiedades tixotrópicas y estructurales de geles moleculares. Se concluye que la formación de geles moleculares tixotrópicos y su recuperación después la aplicación de una deformación destructiva, depende tanto de la fuerza como del tipo de interacciones intermoleculares existentes en las redes fibrilares de los geles.

\section{-Medidas reológicas por inversión de vial}

El más común de los test de gelación es dar la vuelta a un vial con una muestra y ver si fluye o no bajo su propio peso (Figura 1.29). ${ }^{28}$ Se asume que una muestra, gel, tiene un límite de fluencia ( $\sigma_{y}=$ yield stress; esfuerzo inicial necesario para que una muestra fluya), mientras que una muestra viscoelástica que no es un gel presentará una apreciable fluidez. Debido a la facilidad de llevar a cabo esta prueba es un método muy utilizado en los estudios de geles moleculares. Aun así hay que tener cuidado a la hora de interpretar los resultados. Es fácil equivocarse, por ejemplo al considerar líquido un gel con un bajo límite de fluencia. Por todo ello es útil recordar la reología implícita en un test de inversión de vial. 
Lo primero es definir el límite de fluencia que permite que el gel fluya o no.

$$
\sigma_{y}=G \cdot \gamma_{c}(\text { Ecuación 1.1) }
$$

$G$ es el módulo del gel, indica la rigidez de la red fibrilar del gel, mientras que $\gamma_{c}$ es la deformación crítica (Ecuación 1.1) que marca el límite viscoelástico lineal e indica la fortaleza de los enlaces de la red fibrilar. Por lo tanto para que $\sigma_{y}$ sea alto, ambos valores $G$ y $\gamma_{c}$ deben ser altos.

Consideremos una hipotética prueba de inversión de vial de un gel con un límite de fluencia $\sigma_{\mathrm{y}}$ dentro de un vial cilíndrico de radio $R$, con una longitud de gel L (Figura 1.29b). Para este supuesto, la masa de la muestra es $\pi R^{2} L \rho$. La condición de equilibrio estático iguala el límite de fluencia con el estrés gravitacional dando lugar a la siguiente expresión para el límite de fluencia donde $g$ es la aceleración de la gravedad y $\rho$ la densidad.

$$
\sigma_{y} \approx \rho . g . L(\text { Ecuación 1.2) }
$$

Se asume que el límite de fluencia de la muestra coincide con la ruptura de la red estructural del gel. Lo que nos dice la ecuación es que la inversión de vial depende tanto de la masa como del tamaño del vial. La longitud del gel $L$ es proporcional a la masa y densidad de la muestra, e inversamente proporcional al tamaño del vial para una masa concreta. Por todo esto es crucial usar la misma masa y tipo de vial (geometría, tamaño) para poder comparar el comportamiento como gel de un compuesto.

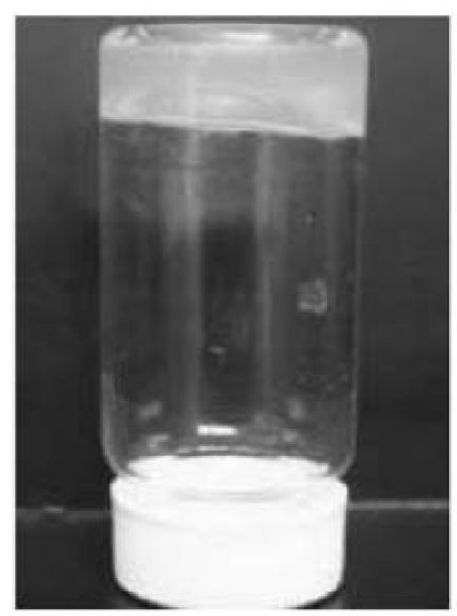

(a)

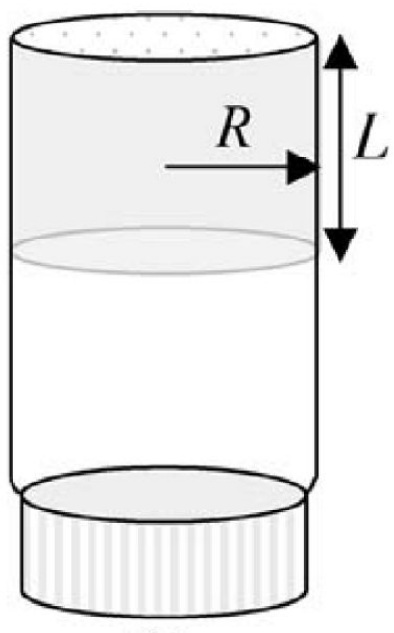

(b)

Figura 1.29: (a) Foto de un gel que pasa la prueba de inversión de vial; (b) la muestra del test se idealiza como un cilindro de radio $R$ y longitud $L .^{28}$ 
Las pruebas con el reómetro pueden confirmar los datos obtenidos, por ejemplo Booth et $a l .{ }^{86}$ estudiaron geles acuosos formados por polímeros usando tanto el método por inversión de vial como la reología convencional. Como ejemplo se puede ver en la Figura 1.30 que los valores de límite de fluencia calculados por inversión (símbolos llenos) o por reología (símbolos vacios) para los diferentes polímeros coinciden sobremanera.

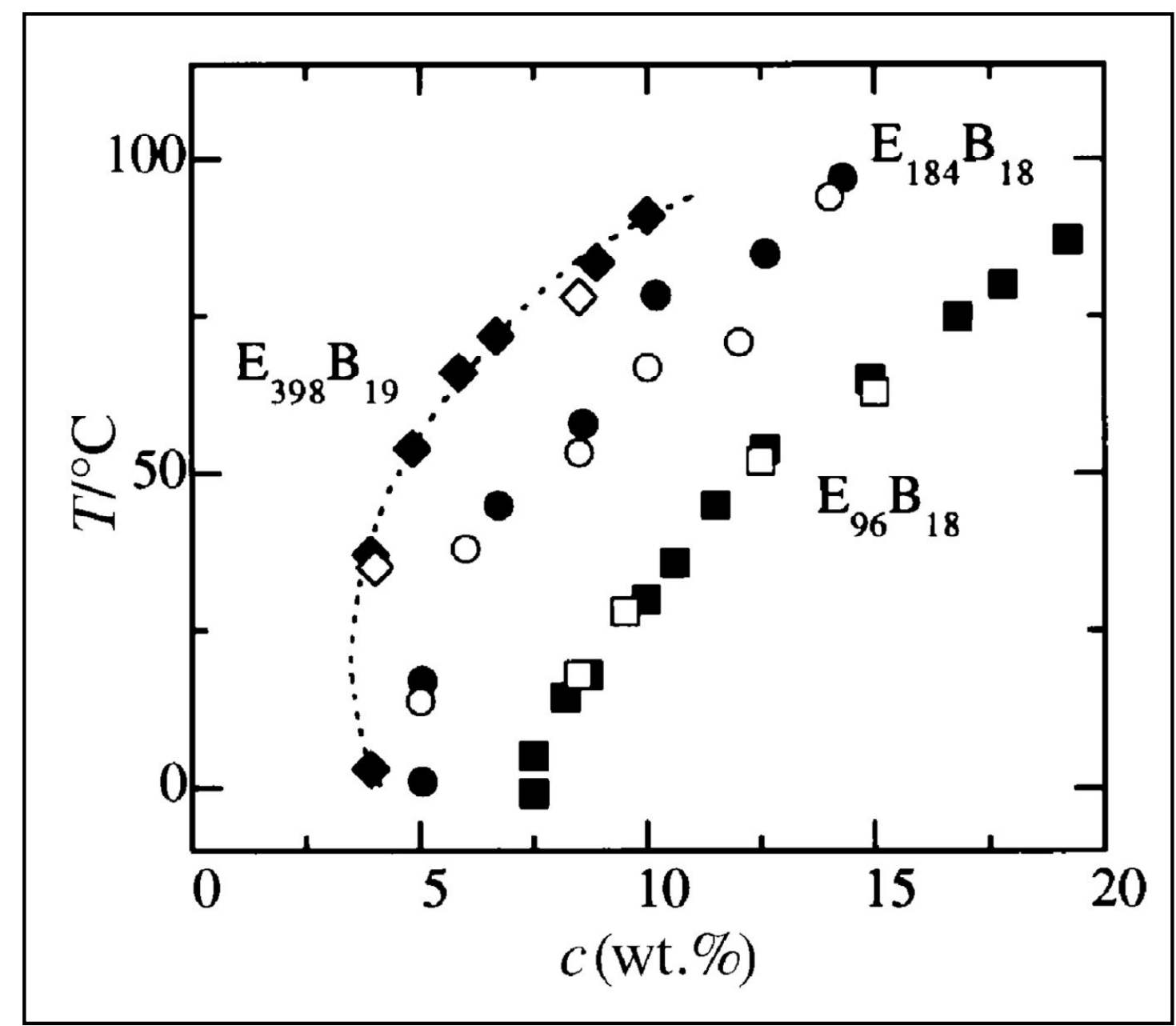

Figura 1.30: Concentraciones mínimas de gelación a diferentes temperaturas de los polímeros E96B18 (cuadrados), E184B18 (círculos) y E398B19 (diamantes), determinadas tanto por inversión de vial (símbolos llenos) o por uso de un reómetro (símbolos vacios). ${ }^{86}$ 


\section{3.- Bibliografía.}

(1) Lloyd, D. Colloid Chem. Theor. Appl. 1926, 767-782.

(2) Rogovina, L. Z.; Vasil'ev, V. G.; Braudo, E. E. Polym. Sci. Ser. C 2008, 50 (1), 85-92.

(3) Flory, P. J. Faraday Discuss. Chem. Soc. 1974, 57 (0), 7-18.

(4) Raghavan, S. R.; Cipriano, B. H. In Molecular Gels: Materials with SelfAssembled Fibrillar Networks; Springer-Verlag: Berlin/Heidelberg, 2006; pp 241252.

(5) Osada, Y. Gels Handb. 2001, 1, 1-25.

(6) Terech, P.; Weiss, R. G. Chem. Rev. 1997, 97 (8), 3133-3160.

(7) Okesola, B. O.; Smith, D. K. Chem. Soc. Rev. 2016, 45 (15), 4226-4251.

(8) Sangeetha, N. M.; Maitra, U. Chem. Soc. Rev. 2005, 34 (10), 821-836.

(9) Miravet, J. F.; Escuder, B. Supramol. Syst. Biomed. Fields 2013, No. 13, 331-354.

(10) Lipowitz, A. Justus Liebigs Ann. Chem. 1841, 38 (3), 348-355.

(11) George, M.; Weiss, R. G. Acc. Chem. Res. 2006, 39 (8), 489-497.

(12) Dastidar, P. Chem. Soc. Rev. 2008, 37 (12), 2699-2715.

(13) Hirst, A. R.; Escuder, B.; Miravet, J. F.; Smith, D. K. Angew. Chemie - Int. Ed. 2008, 47 (42), 8002-8018.

(14) Suzuki, M.; Hanabusa, K. Chem. Soc. Rev. 2009, 38 (4), 967-975.

(15) Smith, D. K. Chem. Soc. Rev. 2009, 38 (3), 684-694.

(16) Steed, J. W. Chem. Soc. Rev. 2010, 39 (10), 3686-3699.

(17) Piepenbrock, M. O. M.; Lloyd, G. O.; Clarke, N.; Steed, J. W. Chem. Rev. 2010, 110 (4), 1960-2004. 
(18) Dawn, A.; Shiraki, T.; Haraguchi, S.; Tamaru, S.; Shinkai, S. Chem. Asian J. 2011, $6(2), 266-282$.

(19) Buerkle, L. E.; Rowan, S. J. Chem. Soc. Rev. 2012, 41, 6089-6102.

(20) Das, D.; Kar, T.; Das, P. K. Soft Matter 2012, 8 (8), 2348-2365.

(21) Kartha, K. K.; Mukhopadhyay, R. D.; Ajayaghosh, A. Chimia (Aarau). 2013, 67 $(1-2), 51-63$.

(22) Yu, G.; Yan, X.; Han, C.; Huang, F. Chem. Soc. Rev. 2013, 42 (16), 6697-6722.

(23) Tam, A. Y.-Y.; Yam, V. W.-W. Chem. Soc. Rev. 2013, 42 (4), 1540-1567.

(24) Babu, S. S.; Praveen, V. K.; Ajayaghosh, A. Chemical Reviews. American Chemical Society February 26, 2014, pp 1973-2129.

(25) Abdallah, D. J.; Weiss, R. G. Adv. Mater. 2000, 12 (17), 1237-1247.

(26) Estroff, L. A.; Hamilton, A. D. Chem. Rev. 2004, 104 (3), 1201-1217.

(27) Fages, F. Low Molecular Mass Gelators; Springer, 2005; Vol. 256.

(28) Weiss, R. G.; Terech, P. Molecular gels: Materials with self-assembled fibrillar networks; 2006.

(29) Beatriu Escuder Ian W Hamley, Jan H Van Esch, J. F. M. Functional Molecular Gels; Escuder, B., Miravet, J. F., Eds.; Royal Society of Chemistry: Cambridge, 2013.

(30) Caran, K. L.; Lee, D. C.; Weiss, R. G. In Soft Fibrillar Materials: Fabrication and Applications; Wiley-VCH Verlag GmbH \& Co. KGaA: Weinheim, Germany, 2013; pp 1-75.

(31) Weiss, R. G. Journal of the American Chemical Society. 2014, pp 7519-7530.

(32) Du, X.; Zhou, J.; Shi, J.; Xu, B. Chem. Rev. 2015, 115 (24), 13165-13307.

(33) Abdallah, D. J.; Sirchio, S. A.; Weiss, R. G. Langmuir 2000, 16 (20), 7558-7561. 
(34) George, M.; Tan, G.; John, V. T.; Weiss, R. G. Chem. - A Eur. J. 2005, 11 (11), $3243-3254$.

(35) Grassi, S.; Carretti, E.; Dei, L.; Branham, C. W.; Kahr, B.; Weiss, R. G. New J. Chem. 2011, 35 (2), 445-452.

(36) Stupp, S.; Zha, R.; Palmer, L.; Cui, H.; Bitton, R. Faraday Discuss. 2013, No. 166, 9-30.

(37) Kiyonaka, S.; Shinkai, S.; Hamachi, I. Chem. - A Eur. J. 2003, 9 (4), 976-983.

(38) Gräbner, D.; Zhai, L.; Talmon, Y.; Schmidt, J.; Freiberger, N.; Glatter, O.; Herzog, B.; Hoffmann, H. J. Phys. Chem. B 2008, 112 (10), 2901-2908.

(39) Minakuchi, N.; Hoe, K.; Yamaki, D.; Ten-no, S.; Nakashima, K.; Goto, M.; Mizuhata, M.; Maruyama, T. Langmuir 2012, 28 (25), 9259-9266.

(40) Desii, A.; Chiellini, F.; Di Stefano, R.; Tiné, M. R.; Solaro, R. J. Polym. Sci. Part A Polym. Chem. 2010, 48 (4), 986-990.

(41) Datar, A.; Balakrishnan, K.; Zang, L. Chem. Commun. 2013, 49 (61), 6894-6896.

(42) Travaglini, L.; Gubitosi, M.; di Gregorio, M. C.; Pavel, N. V.; D’Annibale, A.; Giustini, M.; Soto Tellini, V. H.; Vázquez Tato, J.; Obiols-Rabasa, M.; Bayati, S.; Galantini, L. Phys. Chem. Chem. Phys. 2014, 16 (36), 19492-19504.

(43) Wilder, E. A.; Hall, C. K.; Spontak, R. J. J. Colloid Interface Sci. 2003, 267 (2), 509-518.

(44) Li, J.; Gao, Y.; Kuang, Y.; Shi, J.; Du, X.; Zhou, J.; Wang, H.; Yang, Z.; Xu, B. J. Am. Chem. Soc. 2013, 135 (26), 9907-9914.

(45) Majumder, J.; Deb, J.; Das, M. R.; Jana, S. S.; Dastidar, P. Chem. Commun. 2014, 50 (14), 1671-1674.

(46) Wang, S.; Shen, W.; Feng, Y.; Tian, H. Chem. Commun. (Camb). 2006, 2 (c), 1497-1499.

(47) Yang, X.; Zhang, G.; Zhang, D.; Kawano, S.; Fujita, N.; Shinkai, S.; Orti, E.; 
Guldi, D. M.; Martin, N.; Ihara, H. J. Mater. Chem. 2012, 22 (1), 38-50.

(48) Wang, C.; Chen, Q.; Sun, F.; Zhang, D.; Zhang, G.; Huang, Y.; Zhao, R.; Zhu, D. J. Am. Chem. Soc. 2010, 132 (9), 3092-3096.

(49) Wang, C.; Zhang, D.; Zhu, D. J. Am. Chem. Soc. 2005, 127 (47), 16372-16373.

(50) Naota, T.; Koori, H. J. Am. Chem. Soc. 2005, 127 (26), 9324-9325.

(51) Higashiguchi, K.; Taira, G.; Kitai, J. I.; Hirose, T.; Matsuda, K. J. Am. Chem. Soc. 2015, 137 (7), 2722-2729.

(52) Murata, K.; Aoki, M.; Suzuki, T.; Harada, T.; Kawabata, H.; Komori, T.; Ohseto, F.; Ueda, K.; Shinkai, S. J. Am. Chem. Soc. 1994, 116 (13), 6664-6676.

(53) Kumar, R.; Raghavan, S. R. Soft Matter 2009, 5 (4), 797-803.

(54) Shklyarevskiy, I. O.; Jonkheijm, P.; Christianen, P. C. M.; Schenning, A. P. H. J.; Guerzo, A. Del; Desvergne, J.-P.; Meijer, E. W.; Maan, J. C. Langmuir 2005, 21, $2108-2112$.

(55) Ko, Y. G.; Shin, S. S.; Choi, U. S.; Park, Y. S.; Woo, J. W. ACS Appl. Mater. Interfaces 2011, 3 (4), 1289-1298.

(56) Bonini, M.; Lenz, S.; Falletta, E.; Ridi, F.; Carretti, E.; Fratini, E.; Wiedenmann, A.; Baglioni, P. Langmuir 2008, 24 (21), 12644-12650.

(57) Bachl, J.; Hohenleutner, A.; Dhar, B. B.; Cativiela, C.; Maitra, U.; König, B.; Díaz, D. D. J. Mater. Chem. A 2013, 1 (14), 4577-4588.

(58) Hikmet, R. A. M.; Kemperman, H. Nature 1998, 392 (6675), 476-479.

(59) Bhattacharya, S.; Krishnan-Ghosh, Y. Chem. Commun. 2001, No. 2, 185-186.

(60) Jadhav, S. R.; Vemula, P. K.; Kumar, R.; Raghavan, S. R.; John, G. Angew. Chemie - Int. Ed. 2010, 49 (42), 7695-7698.

(61) Trivedi, D. R.; Dastidar, P. Chem. Mater. 2006, 18, 1470-1478.

(62) Jung, J. H.; Park, M.; Shinkai, S. Chem. Soc. Rev. 2010, 39 (11), 4286-4302. 
(63) Das, U. K.; Banerjee, S.; Dastidar, P. Chem. - An Asian J. 2013, 8 (12), 30223031.

(64) Hughes, N. E.; Marangoni, A. G.; Wright, A. J.; Rogers, M. A.; Rush, J. W. E. Trends Food Sci. Technol. 2009, 20 (10), 470-480.

(65) Toro-Vazquez, J. F.; Morales-Rueda, J.; Torres-Martínez, A.; Charó-Alonso, M. A.; Mallia, V. A.; Weiss, R. G. Langmuir 2013, 29 (25), 7642-7654.

(66) Carretti, E.; Bonini, M.; Dei, L.; Berrie, B. H.; Angelova, L. V; Baglioni, P.; Weiss, R. G. Acc. Chem. Res. 2010, 43 (6), 751-760.

(67) Baglioni, P.; Chelazzi, D.; Giorgi, R.; Poggi, G. Langmuir 2013, 29 (17), 51105122.

(68) Jung, J. H.; John, G.; Masuda, M.; Yoshida, K.; Shinkai, S.; Shimizu, T. Langmuir 2001, 17 (23), 7229-7232.

(69) Hanabusa, K.; Matsumoto, M.; Kimura, M.; Kakehi, A.; Shirai, H. J. Colloid Interface Sci. 2000, 224 (2), 231-244.

(70) Escuder, B.; LLusar, M.; Miravet, J. F. J. Org. Chem. 2006, 71 (20), 7747-7752.

(71) Escuder, B.; Martí, S.; Miravet, J. F. Langmuir 2005, 21 (15), 6776-6787.

(72) Kölbel, M.; Menger, F. M. Chem. Commun. 2001, No. 3, 275-276.

(73) Felip-León, C.; Díaz-Oltra, S.; Galindo, F.; Miravet, J. F. Chem. Mater. 2016, 28 (21), 7964-7972.

(74) Singh, M.; Kundu, S.; Reddy M, A.; Sreekanth, V.; Motiani, R. K.; Sengupta, S.; Srivastava, A.; Bajaj, A. Nanoscale 2014, 6 (21), 12849-12855.

(75) Karimi, A.; Wan Daud, W. M. A. Polymer Composites. June 1, 2015, pp 10861102.

(76) Jung, J. H.; John, G.; Masuda, M.; Yoshida, K.; Shinkai, S.; Shimizu, T. Langmuir 2001, 17 (23), 7229-7232. 
(77) Kumar, D. K.; Jose, D. A.; Dastidar, P.; Das, A. Langmuir 2004, 20 (24), 1041310418.

(78) Barnes, H. A. A Handbook of Elementary Rheology; 2000.

(79) Mark, J. E. Physical properties of polymer handbook; Springer, 2006.

(80) TA instruments. A practical Approach to Rheology. 2015.

(81) Draper, E. R.; Mears, L. L. E.; Castilla, A. M.; King, S. M.; McDonald, T. O.; Akhtar, R.; Adams, D. J. RSC Adv. 2015, 5 (115), 95369-95378.

(82) Mezger, T. G. Applied Rheology: With Joe Flow on Rheology Road; 2014.

(83) Mewis, J.; Wagner, N. J. Adv. Colloid Interface Sci. 2009, 147-148 (C), 214-227.

(84) Barnes, H. H. a.; Barnes, A. J. non_Newtonian fluid Mech. 1997, 70 (97), 1-33.

(85) Ajay Mallia, V.; Weiss, R. G. Soft Matter 2016, 12 (16), 3665-3676.

(86) Kelarakis, A.; Castelletto, V.; Chaibundit, C.; Fundin, J.; Havredaki, V.; Hamley, I. W.; Booth, C. Langmuir 2001, 17 (14), 4232-4239. 


\section{2.- MOTIVACIÓN Y OBJETIVOS.}

Como resultado de la colaboración industrial que mantuvo el grupo en años anteriores se prepararon gelantes moleculares que demostraron ser capaces de estructurar mezclas complejas de surfactantes usadas en bienes de consumo. Se encontró que los resultados más prometedores fueron proporcionados por el compuesto denominado de forma abreviada P12 (ver estructura a continuación) y se publicaron varias patentes que resaltaban la posible aplicación de este y sus compuestos relacionados. ${ }^{1-3}$

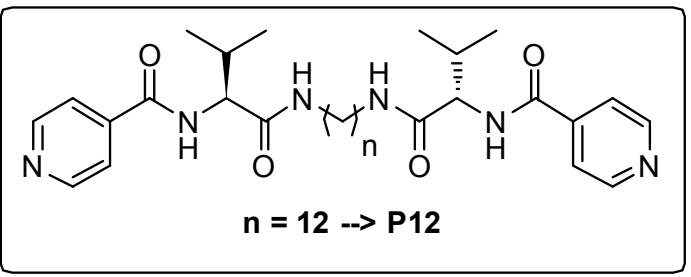

En esta tesis se describen más estudios siguiendo esta línea de trabajo, considerando varios temas relacionados con la aplicación práctica de los hidrogelantes. En primer lugar, se ha descrito en la literatura que la metodología de preparación de geles supramoleculares puede influir en sus propiedades. Por esta razón, en la primera parte del capítulo 3, el objetivo es evaluar cómo afectan a los geles dos métodos diferentes de preparación, cambio de temperatura y cambio de $\mathrm{pH}$. A continuación, una propiedad clave de los materiales es su comportamiento tixotrópico. Para aplicaciones prácticas es deseable una recuperación rápida de los geles después de su ruptura mecánica. Por ello se decidió evaluar cómo la presencia de surfactantes afecta a esta propiedad. Por lo tanto un segundo bloque del capítulo 3 se ocupa de un estudio detallado de las interacciones entre surfactantes (SDS) y los hidrogelantes. Finalmente, la última parte del Capítulo 3 está dirigida al estudio de la recuperación tixotrópica y a comprender algunos factores clave que regulan esta propiedad en geles moleculares.

Teniendo en cuenta el posible uso industrial de los hidrogelantes moleculares, se decidió explorar una nueva familia de compuestos relacionados con P12 pero utilizando funciones de urea en lugar de amidas. Por ello en el capítulo 4 se plantea la preparación de derivados de urea que se consideraban económicamente más asequibles que P12 y 
tetramidas relacionadas, utilizando como material de partida diisocianatos utilizados comúnmente en la industria.

Finalmente, considerando el creciente interés en el uso de hidrogeles supramoleculares en aplicaciones biomédicas, el objetivo del segundo bloque del Capítulo 4 es evaluar la biocompatibilidad de los hidrogeles preparados, es decir, la posibilidad de cultivar células en la matriz del gel.

\section{1.- Bibliografía.}

(1) Fernandez Prieto, S.; Smets, J.; Escuder Gil, B.; Miravet Celades, J. F.; Nebot Carda, V. J. Liquid detergent compositions comprising $\mathrm{pH}$ tuneable amidogellants, and processes for making. US patent 8,222,197, 2011.

(2) Fernandez Prieto, S.; Smets, J.; Escuder Gil, B.; Miravet Celades, J. F.; Nebot Carda, Vi. J.; Tanner Paul, R. Personal care compositions comprising a pH tuneable gellant and methods of using. US patent 9,271,912, 2014.

(3) Miravet Celades, J. F.; Escuder Gil, B.; Nebot-Carda, V. J.; Smets, J.; Fernandez Prieto, S. Encapsulates. US patent 9,644,174, 2013. 


\section{5.- CONCLUSIONES.}

En este trabajo de investigación se han abordado dos cuestiones. En primer lugar el capítulo 3 estudia cómo influyen el método de preparación y la presencia de surfactantes en las propiedades de hidrogeles moleculares. A continuación, en el capítulo 4, se aborda la preparación de nuevos hidrogelantes de tipo bis-urea y el estudio de sus propiedades. Las conclusiones obtenidas son las siguientes:

1) Los hidrogeles formados por los compuestos denominados P3 y P12 presentan propiedades marcadamente diferentes dependiendo que se preparen por cambio de $\mathrm{pH}$ o mediante cambio de temperatura. Dichas propiedades incluyen la concentración mínima de gelación, la cristalinidad y apariencia microscópica de las fibras y el comportamiento reológico. Estos resultados indican que, de acuerdo con algunos estudios previos en la literatura existente sobre geles moleculares, el método de preparación puede ser crucial. Por lo tanto, en los posibles estudios sobre propiedades de interés de los hidrogeles se debería evaluar si el método de preparación es factible en su futura producción a mayor escala. Tal y como se muestra en este trabajo, modificaciones del mismo pueden resultar en cambios dramáticos de propiedades.

2) Los surfactantes, SDS en concreto en este estudio, son capaces de disolver la red fibrilar de los hidrogeles formados por P3 y P12. Este proceso de solubilización puede estudiarse mediante RMN y en particular los experimentos de medida de coeficientes de difusión, permiten distinguir entre el gelante soluble libre y aquel incorporado en micelas mixtas con el SDS. El aumento de la concentración de SDS no afecta a la cantidad de gelante libre en disolución pero por el contrario supone un incremento del mismo solubilizado en micelas mixtas. Esto se traduce en un aumento de la concentración mínima de gelante necesario para la gelación.

3) El estudio de la recuperación de los hidrogeles después de su ruptura mecánica muestra que el tiempo de recuperación depende de la concentración de red fibrilar pero de una manera no lineal. Por debajo de un cierto umbral crítico de concentración de gelante el tiempo de recuperación pasa de ser de unos segundos a varios minutos o incluso horas. Este comportamiento está de acuerdo con que la cinética del comportamiento tixotrópico observado viene determinada por la velocidad de formación de puntos de entrecruzamiento no covalentes entre las fibras y por lo tanto es inversamente proporcional a la concentración de red fibrilar. 
4) El estudio de recuperación tixotrópica, junto con el de la influencia de surfactantes en la cantidad de red fibrilar en los hidrogeles, permite concluir que los surfactantes (SDS) no influyen directamente en la velocidad de recuperación tixotrópica de los hidrogeles. Mientras que la cantidad de red fibrilar varía linealmente con la concentración de SDS, como se ha comentado en el punto anterior, la velocidad de recuperación de los geles sigue un comportamiento altamente no lineal.

5) La preparación de nuevos hidrogelantes de tipo bis-urea a partir de diisocianatos y aminas es altamente eficiente en un solo paso y el aislamiento de los productos es sencillo. Estas características indican que los nuevos hidrogelantes preparados son adecuados para su preparación a gran escala en base a consideraciones de economía de producción.

6) El estudio de una biblioteca de 39 moléculas de tipo bis-urea preparada por variación de los diisocianatos y aminas empleadas ha permitido descubrir 24 hidrogelantes nuevos. No se ha encontrado un patrón claro entre estructura molecular y capacidad de formación de geles. En particular el carácter hidrofóbico de las moléculas $(\log \mathrm{P})$ no es un descriptor que permita predecir la capacidad de hidrogelación.

7) Se ha demostrado que la preparación de los nuevos gelantes de tipo bis-urea puede realizarse en propilenglicol de manera que no se hace necesario su aislamiento y purificación, pudiendo utilizarse la disolución obtenida directamente para la formación de hidrogeles. En particular es de interés que el estudio por RMN demuestra que la reacción es completa y que el exceso de diisocianato se elimina por reacción por el propilenglicol, dando lugar a carbamatos.

8) En el caso de tres compuestos de tipo bis-urea y de P3 y P12 se ha demostrado que sus hidrogeles son compatibles con las líneas celulares estudiadas. Adicionalmente, los hidrogeles muestran una actividad citoestática. 